\title{
The Positional Firing Properties of Medial Entorhinal Neurons: Description and Comparison with Hippocampal Place Cells
}

\author{
Gregory J. Quirk, ${ }^{1}$ Robert U. Muller, ${ }^{1}$ John L. Kubie, ${ }^{2}$ and James B. Ranck, Jr. ${ }^{1}$ \\ Departments of ${ }^{1}$ Physiology and ${ }^{2}$ Anatomy and Cell Biology, State University of New York Health Science Center at \\ Brooklyn, Brooklyn, New York 11203
}

Hippocampal place cells in the rat are so named because they fire predominantly within circumscribed regions of the environment. This study describes the positional firing properties of cells afferent to hippocampal place cells, in superficial layers of medial entorhinal cortex (MEC). MEC cells in these layers project to the hippocampus via the perforant path and, along with lateral entorhinal cells, are the sole route by which cortical information reaches the hippocampus. MEC celis were recorded from rats while they retrieved pellets in simple geometric enclosures. The behavioral task as well as procedures for data collection and analysis were the same used in previous studies on hippocampal place cells (e.g., Muller et al., 1987) in order to facilitate the direct comparison between hippocampal and entorhinal cells. The firing patterns of MEC cells show pronounced locational variations reminiscent of hippocampal firing fields, but with a lower signal-to-noise ratio. While noisy, MEC firing patterns are stationary in time as evidenced by their reproducibility, and the improvement in spatial signal with long-duration recordings. Furthermore, MEC firing patterns are not due to variations in the rat's behavior. Taken together, these data show that the positional firing variations in MEC cells are due to the location-specificity of MEC cells. These and additional data lead us to conclude that location-specific information exists prior to the hippocampus.

MEC cells are similar to hippocampal place cells in that their firing can be controlled by the rotation of a visual cue (a white card attached to the wall), but is not disrupted by removing the cue. An important difference between hippocampal and entorhinal cells was seen when the shape of the recording chamber was changed. In the transition from a cylinder to an equal-area square of similar appearance, MEC firing patterns topologically transformed (or "stretched") while those of hippocampal place cells changed to an unpredictable pattern. We conclude that the positional firing of MEC cells is more "sensory bound" than hippocampal cells, and that the ability to discriminate different environments, while present in the hippocampus, is not yet present in its input from MEC.

Received Aug. 26, 1991; revised Dec. 12, 1991; accepted Dec. 27, 1991.

This work was supported by N.I.H. Research Grants NS 20686, NS 14497, and NS 07114.

Correspondence should be addressed to Gregory J. Quirk, Department of Physiology, Box 31, State University of New York at Brooklyn, Brooklyn, NY 11203.

Copyright @ 1992 Society for Neuroscience $0270-6474 / 92 / 121945-19 \$ 05.00 / 0$
The discovery of "place cells" in the hippocampus of rats (O'Keefe and Dostrovsky, 1971) has generated much interest in the hippocampus as a spatial problem solving machine. Place cells are CA1 and CA3/4 hippocampal pyramidal cells that fire only in a restricted part of the environment called the cell's "firing field." The location-specific firing of place cells along with the spatial problem solving deficits caused by hippocampal lesions led O'Keefe and Nadel (1978) to propose that the hippocampus implements an abstract representation of the environment that they called a cognitive map. By hypothesis, the rat uses the map to calculate efficient paths. The cognitive mapping notion is supported by recent lesion (Olton et al., 1978a; Morris et al., 1982; Jarrard, 1983; Sutherland et al., 1983; Kubie et al., 1989) and single-unit studies (O'Keefe and Conway, 1978; Olton et al., 1978b; McNaughton et al., 1983; Muller and Kubie, 1987; Muller et al., 1987; O’Keefe and Speakman, 1987; Breese et al., 1989; Wiener et al., 1989) and has been influential in guiding hippocampal research. It is proper to add, however, that the hippocampus may serve nonspatial as well as spatial functions (Johnson et al., 1977; Eichenbaum and Cohen, 1988). In addition, the discovery of cells with directional firing correlates in the postsubiculum (Taube et al., 1989a,b) and cells with combined direction and location firing correlates in the subiculum (Sharp et al., 1990b) indicates that structures throughout the hippocampal formation ${ }^{1}$ are involved in spatial representation.

One important line of inquiry that arises naturally from the place cell phenomenon concerns the neural antecedents of location-specific firing. It may be asked if location-specific firing occurs first in hippocampal pyramidal cells, or if neurons in structures afferent to the hippocampus also fire in this fashion. Since entorhinal cortex is virtually the only source of cortical input to the hippocampus that is not relayed through subcortical structures, we focus on entorhinal cortex. Earlier work from this laboratory (Quirk and Ranck, 1986; Quirk and Muller, 1989) and from McNaughton and Barnes' laboratory (Barnes et al., 1990) indicated that cells in entorhinal cortex show significant positional firing variations. One aim of this article is to assess further the strength of such firing variations.

The notion that entorhinal cortex may be involved in processing spatial information is supported by anatomical and lesion studies. Anatomical work indicates that isocortical input

\footnotetext{
${ }^{1}$ The term "hippocampus" refers exclusively to Ammon's horn (Lorente de No's fields CA1-CA4, whereas the term "hippocampal formation" also includes the dentate gyrus, entorhinal cortex, subiculum, presubiculum, postsubiculum, and parasubiculum. The hippocampus, dentate gyrus, and subiculum are classified as allocortex; the presubiculum, subiculum, and entorhinal cortex are called periallocortex; more lateral regions (most of the cortical mantle) are termed isocortex.
} 
to entorhinal cortex is relayed in perirhinal cortex (Witter et al., 1989). ${ }^{2}$ Perirhinal cortex in turn is a site of convergence from areas characterized as higher-level sensory association cortices [Jones and Powell, 1970 (monkey); Deacon et al., 1983 (rat)]. The notion that entorhinal cortex is a necessary way station for sensory information to reach the hippocampus is consistent with findings that entorhinal damage causes deficits in spatial problem solving similar to those caused by hippocampal lesions (Miller and Best, 1980; Olton et al., 1982; Schenk and Morris, 1985; Goodlett et al., 1989). Moreover, entorhinal lesions strongly reduce the fraction of hippocampal pyramidal cells that show location-specific firing (Miller and Best, 1980).

Entorhinal cortex is distinct from other six-layered neocortex in that it is divided into deep and superficial zones by a cellfree layer called the "lamina dissecans" (see Fig. 1). The projection to the hippocampus arises from the superficial zone (layers II-III) and enters the hippocampus via the perforant path. Layer II projects preferentially to the dentate gyrus and CA3, whereas layer III supplies input to CA3 and CA1 (Steward and Scoville, 1976). Thus, the "trisynaptic pathway" from entorhinal cortex to dentate to CA3 to CAI makes up only a portion of the throughput from entorhinal cortex to CA1. Recent electrophysiological work by Yeckel and Berger (1990) shows that the direct influences of entorhinal cortex on CA3 and CA1 are at least as strong as the influences relayed via dentate gyrus.

The deep zone of entorhinal cortex (layers IV-VI) receives a projection from the hippocampus that is relayed via the subicular complex. To a first approximation, then, cells in the superficial zone are the likeliest sources of the sensory information that is necessary to support location-specific firing. In contrast, units in the deep zone probably reflect the outcome of information processing within the hippocampus. This picture is complicated by the existence of intraentorhinal connections from the deep zone to the superficial zone, but not in the reverse direction (Kohler, 1986). Our experiments shed some light on the functional significance of the deep-to-superficial projection.

In the rat and other species, entorhinal cortex is divided into medial and lateral portions. Perirhinal cortex projects mainly to lateral entorhinal cortex, although some fibers go directly to the medial portion. Lateral entorhinal cortex projects strongly to the medial region, and both regions send axons to the entire septal-temporal extent of the dentate gyrus and hippocampus via the perforant path. Our investigations focus on the inputs to the hippocampus that arise from superficial layers of medial entorhinal cortex (MEC). Due to technical considerations, place cells have been described so far only in the dorsal hippocampus. Accordingly, the recordings in the present study are from that part of MEC that projects to the dorsal hippocampus. In addition, we examined the activity of MEC cells in rats that had overlearned an extremely simple behavioral lask that was previously used to investigate place cells (Muller et al., 1987; see also Materials and Methods). This permits us to compare directly positional spatial firing variations of place cells and $\mathrm{MEC}$ cells under identical conditions.

\section{Materials and Methods}

Behavioral training. The task chosen to examine the firing of entorhinal cells was that of Muller et al. (1987), which was a reduced cue environment where the firing of hippocampal place cells can be brought

\footnotetext{
${ }^{2}$ Entorhinal cortex also receives input from limbic cortex and from many noncortical areas including the medial septum, thalamus, hypothalamus, claustrum, amygdala, and brainstem.
}

under the control of a single white card attached to the wall. The recording chamber had cylindrical walls and was $76 \mathrm{~cm}$ in diameter, 51 $\mathrm{cm}$ high, and gray in color. The floor paper, which was replaced after each recording session, was also gray. The cylinder was placed on the floor and was surrounded by a brown curtain to form a circular enclosure, $1.5 \mathrm{~m}$ in diameter and $2 \mathrm{~m}$ high. The cue card subtended $100^{\circ}$ of arc in the cylinder. Normally, the card was centered at 3 o'clock as seen by a fixed TV camera. It was intended that this card serve as a prominent visual cue in the cylinder. In card rotation experiments, the card was moved from the 3 o'clock position to either the 6,9 , or 12 o'clock position. Lighting in the recording room was provided by four $15 \mathrm{~W}$ lamps symmetrically oriented on the ceiling. In addition to the cylinder, a square chamber $69 \mathrm{~cm}$ on a side and $51 \mathrm{~cm}$ high was also used. A white card was placed on the wall that corresponded to the normal position of the card in the cylinder.

During training, rats were food deprived to approximately $80 \%$ of their normal body weight, and maintained that way throughout the experiment. Each rat was handled once a day for $2 \mathrm{~d}$, and on the third day was placed in the cylinder for the first time. Food pellets were scattered on the floor of the cylinder, and rats eventually started to eat the pellets. Daily training sessions in the cylinder lasted about $15 \mathrm{~min}$ and pellets were dropped in at a rate of three to four per minute. Rats sampled the entire floor in pursuit of the scattered pellets. After approximately $10 \mathrm{~d}$, rats spent almost all of their time moving in the chamber. Twenty-five rats were trained in this way. Following training in the cylinder, 15 of the rats received similar training in the square chamber, where they quickly adapted. At the end of training, the rats had received, in total, approximately 15 exposures to the testing chamber over a period of 2 weeks. The rats were intentionally overtrained in this simple task, so that cells could be examined in the behavioral steady state, following a presumed initial learning period.

Electrode implantation. Following training, 25 rats were surgically implanted with a chronic microdrive for recording extracellular action potentials from single cells (Kubie, 1984). The only modification of the drive's original design for implanting entorhinal cortex was to make it several millimeters longer. The drive consisted of a movable bundle of 10 Formvar-insulated wires, each $25 \mu \mathrm{m}$ in diameter, with tips cut square and of equal length. Just prior to implantation, the tips were coated with carbowax to prevent bending. The drive was advanced by turning three screws attached to the electrode assembly. Surgery was performed under Nembutal anesthesia $(50 \mathrm{mg} / \mathrm{kg})$. Skull coordinates used to reach entorhinal cortex were as follows: $4.0 \mathrm{~mm}$ posterior to bregma, $5.2 \mathrm{~mm}$ lateral to the midline, $30^{\circ}$ angled caudally in the sagittal plane, and $4.5 \mathrm{~mm}$ ventral to the surface of the brain. This placed the tip of the electrode just deep to, and normal with respect to, layer VI of entorhinal cortex. In addition to the entorhinal electrode array, 10 of the 25 rats also were implanted with a pair of EEG electrodes $(78 \mu \mathrm{m}$ in diameter) in the contralateral hippocampus $(3.5 \mathrm{~mm}$ posterior, 2.0 $\mathrm{mm}$ lateral to bregma, $2.5 \mathrm{~mm}$ ventral to the dura). Of the remaining 15 rats, 11 had hippocampal electrodes implanted ipsilaterally rather than contralaterally (coordinates: $3.5 \mathrm{~mm}$ posterior to bregma, $2.0 \mathrm{~mm}$ lateral to the midline, $2.25 \mathrm{~mm}$ ventral to the dura) to stimulate the perforant path in the hippocampus in order to backfire projection cells in the entorhinal cortex. To anchor the electrode, skull screws were implanted over the cerebellum and in the frontal bone. The feet of the electrode drive were cemented to the skull using Grip Cement. A topical antibiotic (Neosporin) was applied around the wound at the end of surgery. Rats werc allowed 1 weck to recover before testing for unit activity.

At the completion of an experiment, rats were killed with an overdose of Nembutal and perfused transcardially. Just prior to death, positive current was passed on one of the wires just to produce an iron deposit at the electrode tip that could be visualized following reaction with potassium ferrocyanide (Prussian blue). The brains were removed, cut into $40 \mu \mathrm{m}$ frozen sections, and Nissl stained. The positions of cells encountered throughout the electrode's trajectory were calculated back from the blue spot. In 8 rats, no blue spot was found because the electrode was advanced through layer I and out of the brain. For these rats, the recording journal indicated the point at which no further unit activity was recorded; this point was taken to be the layer I/II border (since layer I contains no cell bodies). The assignment of cells to specific layers is somewhat tentative, as it is known that the wircs can move somewhat when passing through brain. In two rats, no electrode track or spot was visible in entorhinal cortex, and the data were discarded.

Unit recording. The unit recording and data collection procedures are 
identical to those originally described by Muller et al. (1987). Rats werc screened daily for unit activity. This consisted of placing the rat in the cylinder and checking all 10 wires for action potentials with a signalto-noise ratio high enough to be adequately discriminated from background activity. The electrode was connected to an FET source follower mounted on the rat's headstage and amplified 1000 times with a Grass preamplifier ( $300 \mathrm{~Hz}$. to $10 \mathrm{kHz}$ bandpass, $6 \mathrm{~dB}$ /octave). To aid in discrimination, active filters with sharper roll-off were occasionally used. Because these filters can distort the appearance of the action potentials, they were turned off prior to making measurements of the waveforms. Once a suitable cell was observed, three window discriminators (Bak time-amplitude, model DIS-1) connected in series were used to select the desired waveform. Acceptance pulses from the last discriminator went to a computer and were counted as action potentials. If no units could be discriminated, the microdrive was advanced $50 \mu \mathrm{m}$.

Once a unit was properly discriminated, an automatic data collection session commenced. A video camera mounted on the ceiling of the recording room was connected to a spot detector, which monitored the position of an incandescent light bulb attached to the headstage of the rat. During the recording session, the output of the window discriminator and the spot detector was sent to a microcomputer (Hewlett Packard, model HP 86) that sampled the position of the rat and spike count 60 times per second. The scanning region of the camera was divided into a $64 \times 64$ array of square pixels ( 6 bits for each dimension), each pixel corresponding to $2.9 \times 2.9 \mathrm{~cm}$ of area in the cylinder.

At the conclusion of the recording session, the spike and location data were transferred to a Masscomp 5500 minicomputer and analyzed. Two $64 \times 64$ arrays were generated from the data. Each element in the first array (spikc array) accumulated the total number of spikes that occurred in each pixel for the entire recording session. Each element in the second array (time array) contained the total time the rat spent in each pixel. Dividing the spike array by the time array yielded a firing rate array. The rate array can be visualized as a firing rate map, which is an overhead view of the recording chamber with each pixel color coded for time-averaged firing rate. White pixels were never visited by the rat. Yellow pixels were visited, but the cell never fired there. Pixels with greater-than-zero firing rate are sorted into ascending order and divided into five color-coded firing rate categories. From the lowest firing rate category to the highest, the colors used are orange, red, green, blue, and purple.

The valucs of the firing rate cutoffs for the color categories are "autoscaled" for each map (Muller et al., 1987) and depend on the range of firing rates observed in the recording session. When a series of recording sessions is run for a given cell, the firing rate categories are determined according to the first map and are the same for the second and subsequent maps. Changes in firing rate of a cell across sessions can be assessed by comparing the number of pixels within a category across maps.

Protocol. Cells were selected for recording if they could be adequately isolated; there was no preselection based on the apparent firing correlates. Consecutive recording sessions were performed until the cell could no longer be held, usually $1-2 \mathrm{~d}$. The waveforms of all cells were photographed with a Polaroid camera. In cases where cells were held for more than $1 \mathrm{~d}$, the waveform and firing pattern were inspected for constancy across days. Recording sessions were either 16 or $24 \mathrm{~min}$ in duration. Between sessions, rats were returned to their home cages and the floor paper in the recording chamber was replaced. Specific protocols varied with each experiment and will be detailed in the Results. To answer specific questions about entorhinal firing patterns, programs were written to analyze the time, spike, and rate arrays that resulted from each recording session. The following is a description of the most frequently used routines.

Measuring the reproducibility between two firing patterns. It was often necessary to measure the degree of reproducibility (similarity) between two rate maps. The reproducibility measure consisted of a pixel-bypixel firing rate cross-correlation (Muller et al., 1987). The firing rate of each pixel in one rate array was paired with the firing rate of the corresponding pixel in the second rate array, resulting in a single correlation valuc. To avoid the ceiling effect associated with correlations, and to obtain a normal distribution, the Fisher $r$-to- $Z$ transform was used: $Z=0.5 \times \log _{c}((1+r) /(1-r))$. This $Z$ value was used as the estimate of reproducibility of firing.

In assessing the reproducibility between firing patterns in the cylinder and square chambers, it was necessary first to transform the square map into a cylindrical map and compare them as two cylinders. A program was written to transform the square firing pattern topologically into a circular firing pattern, transcribed within the square, using a "contracting" algorithm. Each pixcl in the square was moved toward the center (along a ray from the center) a distance proportional to the radius of the circle divided by the distance between the center and the edge of the square at that point. Firing rates of the new pixels in the transformed map were obtained by taking a weighted average of the old pixels, each of which was subdivided into 25 subpixels. This resulted in some spatial averaging in the transformed map.

Measuring the strength of the location-specific signal. The degree of spatial variation in the firing patterns was assessed by measuring the smoothness of firing rate contours. The measure, called spatial coherence, is a nearest neighbor, two-dimensional spatial autocorrelation, and estimates the local orderliness of the firing pattern (Muller and Kubie, 1989). If firing rate is highly correlated with position, changes in rate between neighboring pixels should be small, and the firing rate in a given pixel should be highly correlated with that of its neighbors. Specifically, the firing rate of a given pixel was correlated with the aggregate firing rate of its eight neighbors: the four pixels directly adjacent plus the four corner pixels. This was done for every pixel in the map to produce a single correlation that was then converted into a $Z$ value (spatial coherence).

In comparing firing patterns in the cylinder and the square, two additional measures were used: the number of high-rate patches and the firing area (Muller and Kubie, 1989). The number of high-rate patches is also a measure of smoothness and is a count of the purple, blue, or green pixels occurring singly or attached to pixels of the same color by at least one side. Firing area is a count of pixels in the rate map with a firing rate of greater than 0 . Firing area is smaller in maps where the firing is grouped around one or two high-rate regions, but is larger for firing patterns that are more spread out. It should be noted that the local orderliness of a firing pattern is not the only way of assessing the degree of spatial variation. These tests, however, have proved useful in previous work (Muller and Kubie, 1989).

Measuring the degree of rotation between two firing patterns. To measure the degrec of angular rotation between two firing patterns, the angular cross-correlation was used (Muller and Kubic, 1987). The first step in measuring the angular cross-correlation was to divide cach of the two rate maps into 60 wedges, each $6^{\circ}$ of arc, and calculate the firing rate in each angular bin. Next, the correlation between the two sets of bins was calculated with no rotation. Then, one set of bins was rotated $6^{\circ}$ relative to the other, and the correlation was recalculated. This was repeated until a correlation value was obtained for all 60 positions. The rotation that resulted in the highest corrclation valuc was taken as the estimate of the observed rotation between the two maps. In experiments where a rotation was induced by rotating the cue card, the difference between the intended rotation and the observed rotation was the estimate of the error of rotation for that cell.

\section{Results}

\section{Cell sample}

Recordings were made from 73 MEC cells from 23 rats. Histological analysis revealed that 22 of the electrode tracks were in the center of MEC; the remaining track passed through intermediate entorhinal cortex. The inset of Figure 1 shows the clectrode placements in the 23 rats superimposed on a view of the caudal surface of the rat brain (Haug, 1976). The placements were such that cells in the selected part of MEC are expected to project to the dorsal hippocampus (Ruth et al., 1982). For purposes of comparison, a sample of 33 dorsal hippocampal place cells recorded for previous work from this laboratory were used (Muller and Kubic, 1987; Muller et al., 1987; Quirk et al., 1990). For both MEC and hippocampal cells, the recording environment and trained behavior were the same as were used earlier to investigate place cells (Muller et al., 1987). No discrepancies were found between hippocampal place cell properties in the present and previous work.

The majority of entorhinal cells recorded were from superficial layers (inputs to the hippocampus); only 4 of the 59 cells that could be assigned to a specific layer on histological evidence 
Figure 1. A micrograph of a horizontal section through the hippocampus taken $6 \mathrm{~mm}$ below the skull surface. Identified structures are dentate gyrus $(D G), C A 3$, and $C A I$ of hippocampus, subiculum $(S U B)$, presubiculum $(P R E)$, parasubiculum (PARA), medial entorhinal cortex $(M E C)$, intermediate entorhinal cortex $(I E C)$, lateral entorhinal cortex ( $L E C)$, lamina dissecans $(L D)$, and the rhinal fissure $(R F)$. A lesion from an entorhinal recording electrode produced the dark spot visible in layer II of MEC. Inset, The caudal surface of the right hemisphere of the rat brain showing the placement of entorhinal electrodes in the 23 rats used in the study. Abbreviations: occipital cortex $(O C C)$, medial $(28 M)$ intermediate $(i)$ and lateral $(28 L)$ entorhinal cortex, a second medial transition zone ( $28 M$ ) , transitional cortex $(T R)$, and pyriform cortex $(P Y R)$ (redrawn from Haug, 1976).

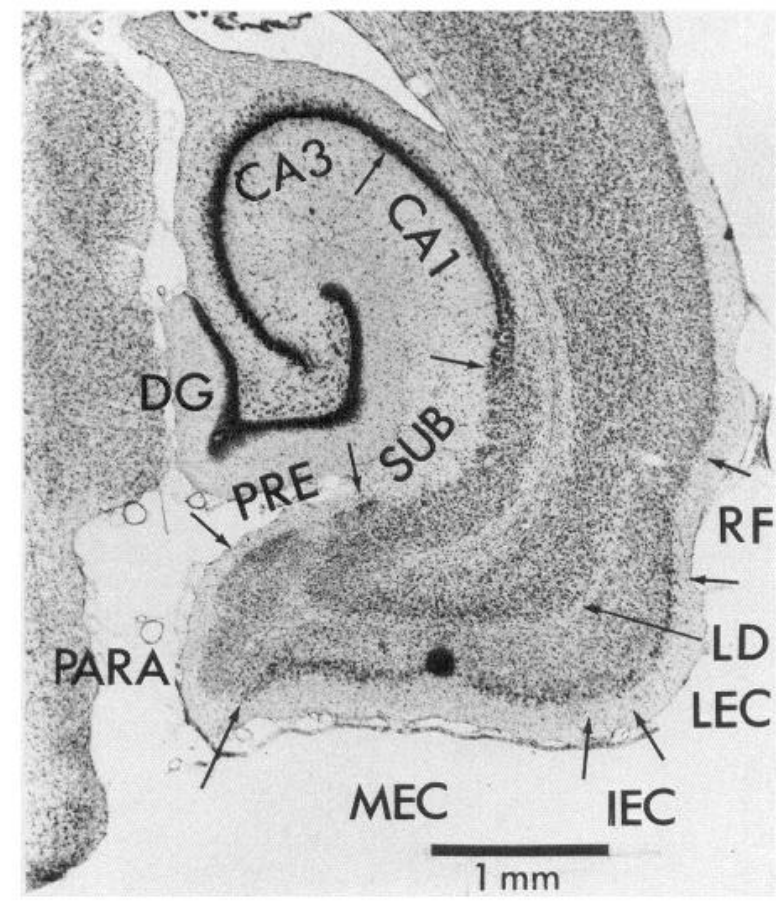

(Table 1) were recorded deep to lamina dissecans (layers IIIVI). Why the recording electrode failed to isolate cells from deep layers as it traversed the entorhinal cortex is unknown. Possible explanations are that most deep MEC cells are normally silent, that they are smaller than superficial MEC cells, or that their inputs are destroyed by the recording electrode. For consistency, the present analysis will be restricted to the 55 MEC cells confirmed to be in superficial layers.

\section{Basic firing properties of entorhinal cells}

The mean duration of unfiltered extracellular spikes of 55 superficial MEC cells (the time between departure and return to the baseline crossings) was $0.30 \mathrm{msec}( \pm 0.09 \mathrm{msec}$ SD). The duration range thus overlaps the $0.3-0.5 \mathrm{msec}$ range for hippocampal complex-spike (pyramidal) cells (Ranck, 1973). Complex-spikes were never observed in MEC units, although short periods of high-frequency (e.g., $150 \mathrm{~Hz}$ ), nondecremental bursting were not uncommon.

Entorhinal cells were recorded while rats retrieved food pellets in the cylindrical chamber. The mean firing rate of the 55 entorhinal cells (time averaged over the $16 \mathrm{~min}$ ) was $7.12 \mathrm{~Hz}( \pm 9.0$ $\mathrm{Hz} \mathrm{SD})$. This is considerably greater than the mean rate for hippocampal complex-spike cells $(1.67 \pm 1.1 \mathrm{~Hz} \mathrm{SD})[t=3.4$; $p(t>3.4)<0.001 ; \mathrm{df}=86]$. The time-averaged firing rate of

Table 1. Spatial coherence, by layer, of entorhinal cells that could be assigned to a specific layer

\begin{tabular}{lllll} 
Layer & $n$ & Mean & SD & Range \\
\hline 2 & 34 & 0.38 & 0.2 & $0.10-0.95$ \\
2.5 & 12 & 0.41 & 0.2 & $0.06-0.79$ \\
3 & 6 & 0.44 & 0.2 & $0.16-0.78$ \\
3.5 & 3 & 0.26 & 0.1 & $0.22-0.31$ \\
$4-6$ & 4 & 0.31 & 0.2 & $0.20-0.53$
\end{tabular}

All recording sessions were $16 \mathrm{~min}$ in duration. entorhinal cells also showed more variance than the complexspike cells $(F=67.0 ; p \ll 0.001)$. This suggests a heterogeneity of cell types; however, in all subsequent analyses no grouping of cells into different classes was observed. Accordingly, all superficial MEC cells will be treated as a single group.

A characteristic feature of hippocampal place cells is their low firing rate outside the firing field, which approaches zero (Muller et al., 1987). Depending on the sequence of positions for the rat, it is possible for these cells to be silent for tens of seconds. Entorhinal cells, on the other hand, were rarely quiet for long periods. An interspike interval analysis was performed to show that place cells and entorhinal cells can be distinguished on this basis. The spike trains of 32 out of $33(97 \%)$ hippocampal complex-spike cells contained intervals of $12 \mathrm{sec}$ or greater. In contrast, only 19 of $55(35 \%)$ MEC cells had one or more interspike intervals greater than $12 \mathrm{sec}$. The low occurrence of long intervals suggests that the relatively high mean firing rates of entorhinal cells is not due to occasional high-frequency bursting but instead to maintained firing at intermediate rates.

\section{Qualitative description of the firing correlates of medial entorhinal units}

Direct observation of rats behavior during pellet retrieving revealed no convincing correlations with MEC cell discharge (monitored by transducing spikes into audible clicks). In common with hippocampal place cells (Muller et al., 1987; Bostock et al., 1991), we saw no tendency of action potentials to occur in association with a particular behavioral state (e.g., walking, eating, grooming, rearing). A more formal analysis, done by marking spike/position samples according to behavioral state by pressing coded buttons during recording sessions, also showed no excess or deficit of MEC spikes associated with grooming, rearing, or still-alert behavior.

In addition to the lack of behavioral correlation for MEC cells, direct observation was not sufficient to uncover a tendency for location-specific firing in all but a few units. This is in marked 
A
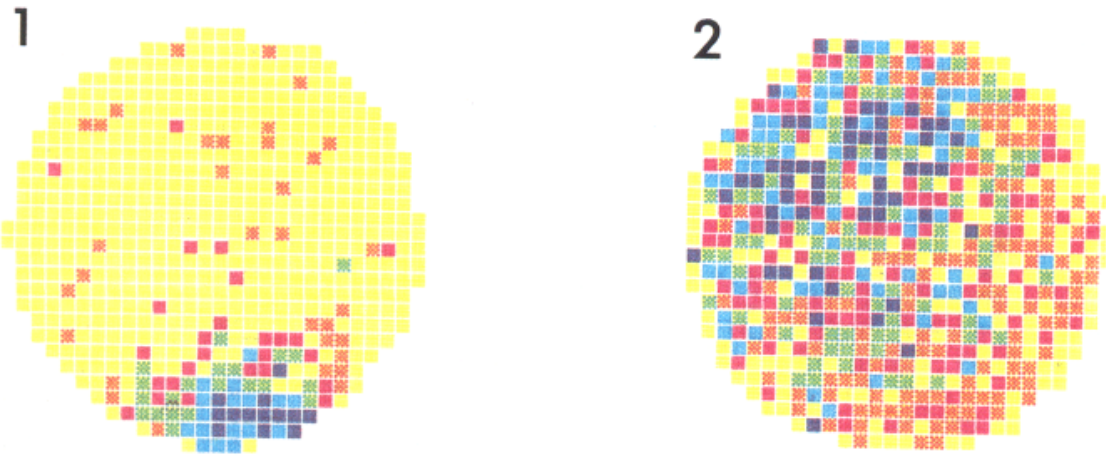

B

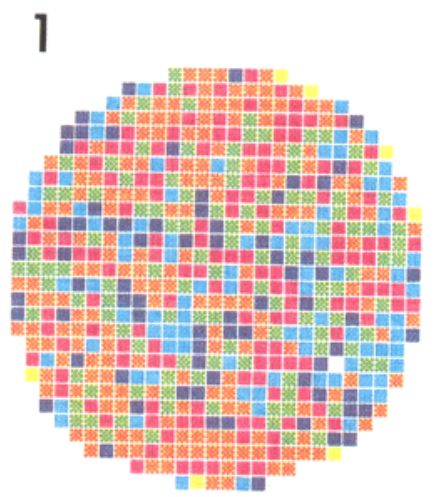

3

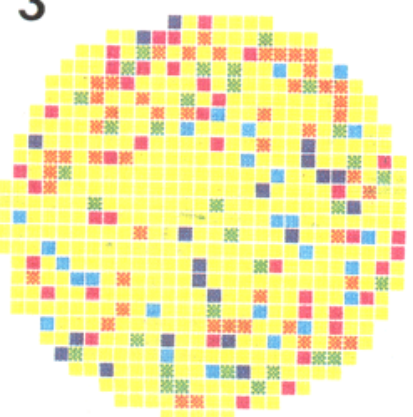

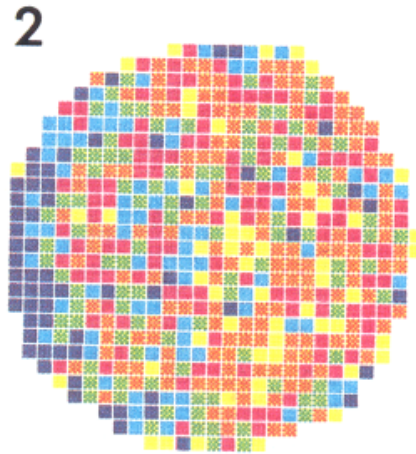

4

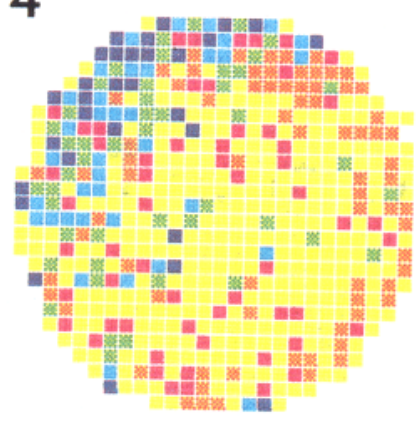

Figure 2. A, Examples of firing rate maps of a hippocampal place cell $(A I)$ and a typical entorhinal cell $(A 2)$. Four additional representative entorhinal cells are shown in B1-4. The maps represent an overhead view of the cylindrical recording chamber in which the rat's position is correlated with the cell's firing rate, averaged over the recording session. In these and all subsequent figures the duration of the recording session was $16 \mathrm{~min}$ (except where specifically noted). Pixels are color coded for firing rate. In these and subsequent maps, yellow indicates a firing rate of exactly 0 . Nonyellow pixels are, from lowest to highest, orange, red, green, blue, and purple. The firing rate (in $\mathrm{Hz}$ ) of the median pixel in each category for each of the maps in this figure is as follows: $A 1$ : $0,0.5,1.7,5.6,12.2,16.8$; $A 2$ : $0,0.8,1.5,2.3,3.5,5.4 ; B 1: 0,17.8$, $22.2,25.5,29.2,33.3 ; B 2: 0,1.8,3.3$, $4.6,6.4,9.5 ; B 3: 0,0.3,0.6,0.9,1.3$, $2.0 ; B 4: 0,0.5,0.9,1.4,2.3,4.2$. The spatial coherence scores for each map are as follows: $A 1,1.41 ; A 2,0.51 ; B 1$, $0.29 ; B 2,0.68 ; B 3,0.01 ; B 4,0.55$. contrast to hippocampal place cells, whose positional correlate is easily detected, even by naive viewers of videotapes (Best and Ranck, 1982). Accordingly, the much more sensitive technique of automatically recording parallel position and spike time series was applied, to see if MEC cells carry a detectable spatial signal.

\section{Spatial analysis of entorhinal cells with the video tracking system}

Firing rate maps obtained with the video tracking system are shown in Figure $2 A$ for a typical hippocampal place cell (A1) and a typical MEC cell (A2). Notice that, unlike the place cell, the MEC cell fired rapidly throughout the chamber, but the two are alike in that the firing reaches a peak at a single position in the cylinder. Four additional MEC cells are shown in Figure $2 B$. Cells B1 and B3 fired fast and slow, respectively, and showed little spatial variation across the cylinder. In contrast, cells B2 and B4 showed clear clusters of higher-than-background activity. The spatial firing pattern of these cells is, however, noisier than is generally the case for place cells.

To provide a partial quantitative description of the spatial firing distributions of MEC and hippocampal place cells, we calculated a measure of the local orderliness of firing patterns that we refer to as "coherence" (Muller and Kubie, 1989; Kubie et al., 1990). Coherence is a nearest neighbor, two-dimensional spatial autocorrelation. The coherence values for the firing patterns shown in Figure 2 suggest that coherence is a reasonable measure of the strength of the spatial signal judged by visual inspection; for maps A1 (place cell) and A2, coherence scores were 1.41 and 0.51 , respectively. For maps $\mathrm{B} 1-4$, coherence scores were $0.29,0.68,0.01$, and 0.55 , respectively. To validate further the measure, seven judges were asked to score each of the 55 rate maps on a scale of 1 to 5 , from "weakest spatial 


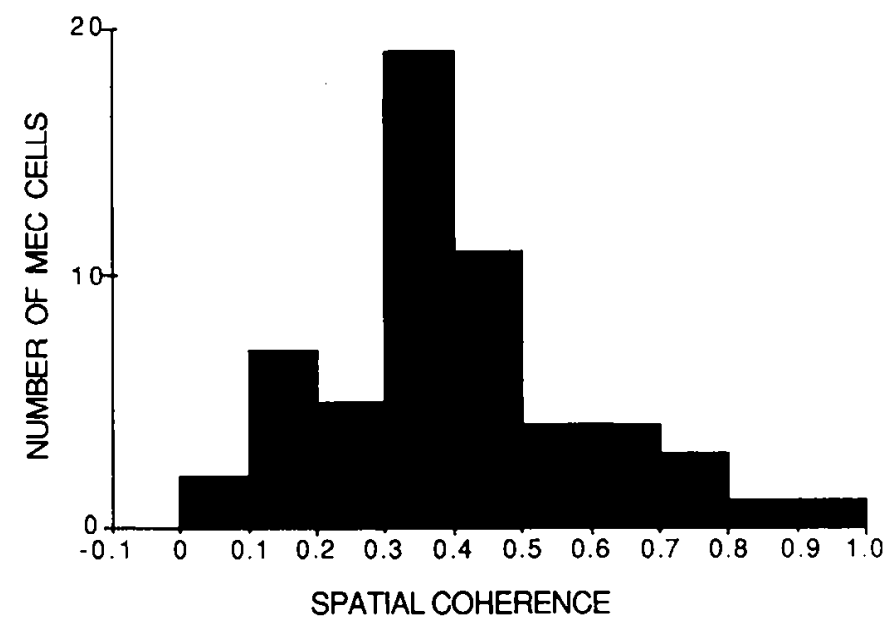

Figure 3. A histogram of the spatial coherence for 57 MEC cells Spatial coherence is a spatial autocorrelation and measures the local "orderliness" of a firing pattern. Spatial coherence appears normally distributed, with no obvious subclasses.

signal" to "strongest spatial signal." The viewers were generally familiar with color-coded rate maps, but not with these particular maps or their coherence scores. The average judgments were highly correlated with coherence $(r=0.81)$, suggesting that coherence accurately captures an aspect of the subjective strength of the spatial signal.

The mean coherence value for $55 \mathrm{MEC}$ cells after $16 \mathrm{~min}$ of recording was $0.358 \pm 0.18 \mathrm{SD}$ (range, $0.13-0.92$ ), significantly lower than the average of 1.23 for hippocampal place cells $(t=$ $20.8 ; p \ll 0.001 ; \mathrm{df}=86$ ). The coherence distribution (Fig. 3) is unimodal, reinforcing the impression from visual inspection of rate maps that there is no reason to divide the cells into subgroups by this criterion.

In principle, the wide coherence range for $\mathrm{MEC}$ cells could arise from imperfect discrimination of neighboring units, so that the firing of several units was admixed. In this case, a positive correlation between amplitude of the target waveform and coherence would be expected since larger waveforms are usually more easily discriminated. The low amplitude/coherence correlation $(r=-0.06)$ argues against the quality of unit discrimination as responsible for the range in coherence scores, although this possibility cannot be positively ruled out.

\section{Spatial cells are found throughout the depth of $M E C$}

The stratification of projections that connect the hippocampus and MEC (see introduction) makes it important to assess the positional firing properties of cells according to their depth in the MEC. Table 1 shows the mean coherence of MEC cells sorted by cortical layer. The position of cells that were assigned to the border between two layers are represented as 2.5,3.5, and so on. An ANOVA revealed no significant difference between layers $(\mathrm{df}=4,45 ; F=0.90)$. The mean coherence for all supcrficial cells combined was 0.40 and was not statistically different from the mean for deep layers of $0.31[t=0.60 ; p(t>0.606)=0.28$; $\mathrm{df}=57]$.

In one case, it was possible to drive a layer II MEC cell antidromically with hippocampal stimulation. Antidromic activation was confirmed with the collision test (Fuller and Schlag, 1976). The firing pattern of the cell was typical of other MEC cells, further supporting the claim that the spatial signal ob- served in superficial MEC neurons actually supplies information to hippocampal cells.

\section{Stationarity of entorhinal firing patterns}

The spatial variations observed in the entorhinal rate maps are suggestive that entorhinal cells fire in relation to the location of the rat in the cylinder; such firing has been called "locationspecific" (Muller et al., 1987). There are, however, other processes that could result in firing rate maps of the kind observed for entorhinal cells, namely, location-correlated and locationindependent firing. Firing is called location-correlated if a unit discharges whenever a nonspatial event occurs, if it is also truc that the event tends to happen in a certain place. For example, a cell in visual cortex might discharge only in a certain part of the environment because its receptive field is adequately stimulated only in that region. Alternatively, a cell might fire in association with a particular behavior that is emitted only in particular places.

Location-independent firing is not spatially fixed but may nevertheless result in apparent positional firing variation due to chance or inadequate sampling of the firing rate across the accessible space. We reserve the term "location-specific firing" for the case in which position itself is the primary correlate. Since location-specific firing is a type of location-correlated firing, we first address the question of whether MEC activity is location-correlated, and then consider the issue of whether it is also location-specific.

The essential criterion to establish that firing is location-correlated is to show that the spatial firing pattern is stable in time (stationary). To this end, we will demonstrate that repeated measurements of the spatial firing pattern have a high degree of similarity (reproducibility). Wc will also show that the strength of the spatial signal increases with increased recording time. This is important since location-independent firing components should eventually produce no positional firing variations. It is useful to note that the spatial firing patterns of hippocampal place cells have been shown to be both reproducible (Muller et al., 1987; Thompson and Best, 1989) and to improve with sampling time (Muller et al., 1987).

Reproducibility of entorhinal firing patterns. Figure $4 B$ shows rate maps from consecutive pairs of recording sessions for three MEC cells; for comparison, a pair of maps for a hippocampal place cell are shown in Figure 44. By inspection, the reproducibility of the map pairs in Figurc $4 B, 1,3$, and 5 , were judged good, fair, and poor, respectively; the reproducibility for the cell in Figure $4 B 1$ was considered about as good as that for the place cell.

Reproducibility was numerically estimated by calculating $Z$ transform of the pixel-by-pixel correlation for the firing distributions of consecutive recording scssions (Muller et al., 1987). The reproducibility for the three MEC cells in Figure 4 was 0.49 , 0.13 , and 0.02 , and for the place ccll 0.56 . The average reproducibility for $33 \mathrm{MEC}$ cells recorded in two or more sessions was $0.12+0.1 \mathrm{SD}$, which corresponds to the reproducibility seen in the cell in Fig. 4B3. The mean for MEC cells was significantly greater than zero $[t=5.6 ; p(t>5.6) \ll 0.001$; df $=$ 32 ], implying the existence of a stationary positional signal in the firing of MEC cells that is detectable after $16 \mathrm{~min}$ of recording; if the null hypothesis of no location-correlated firing were true, the average reproducibility would be zero.

In principle, coherence and reproducibility could be independent of each other. For example, coherence could be low if the 

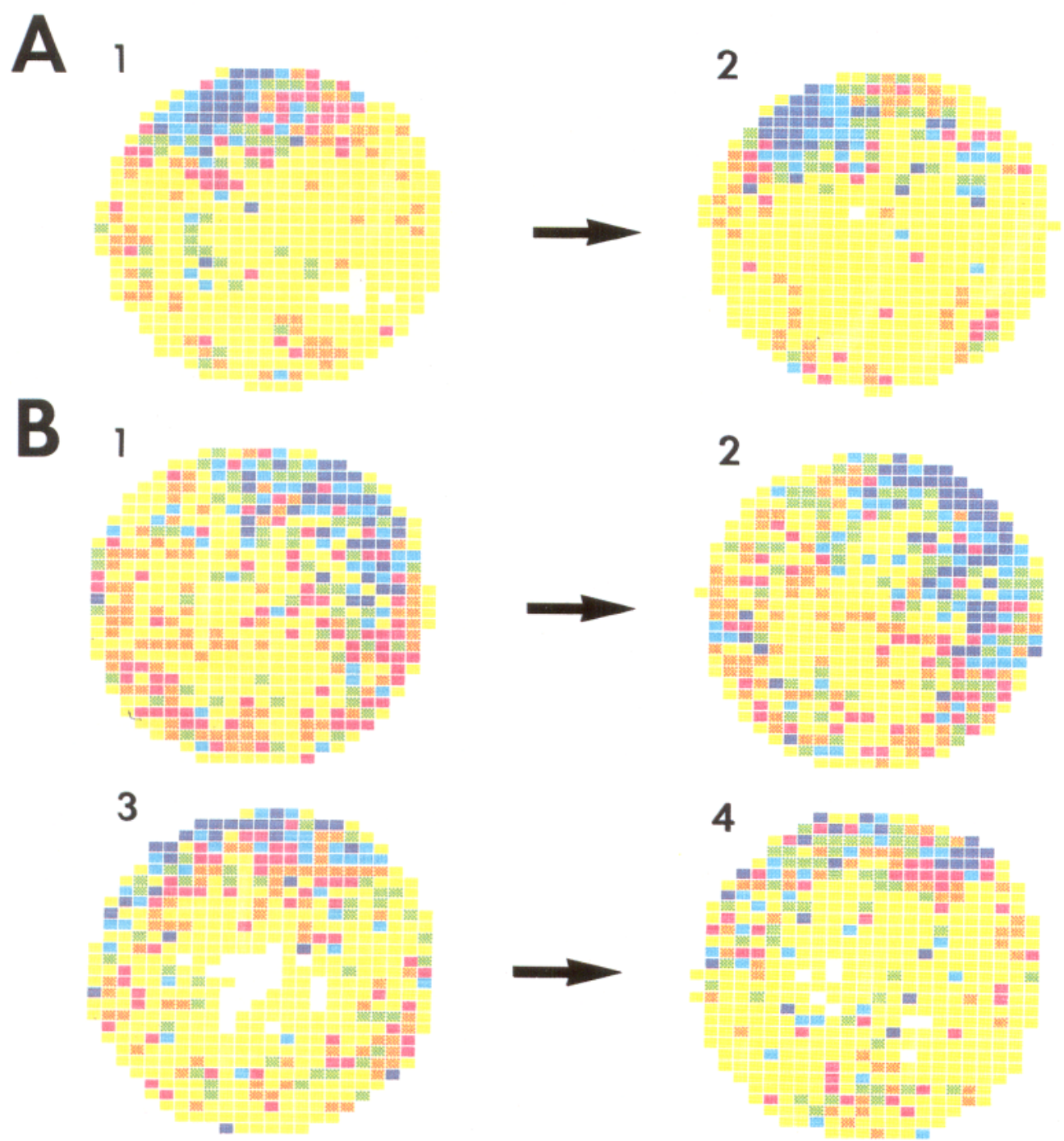

5

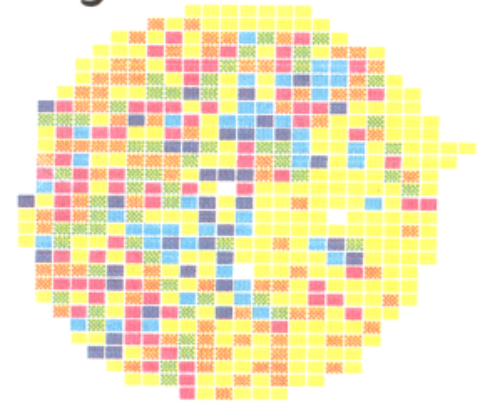

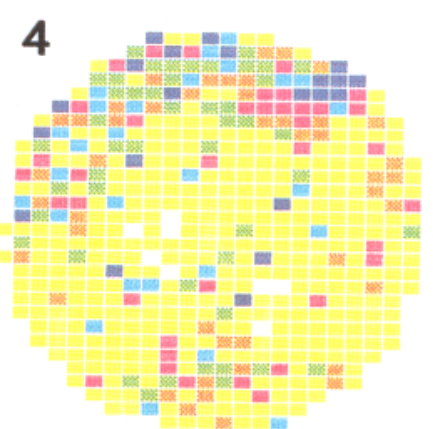

6

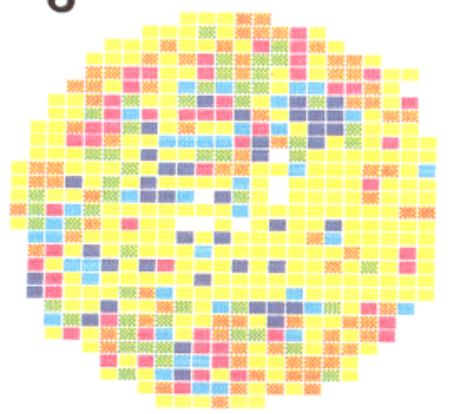

Figure 4. Replications of recording sessions to show the reproducibility of the spatial firing pattern for a hippocampal place cell $(A)$ and three representative entorhinal cells $(B 1,3,5)$, demonstrating strong, average, and weak reproducibility, respectively. The reproducibility of each cell was, for cell $A, 0.56$; cell B1, 0.49; cell B2, 0.13; cell $B 3,0.02$. The spatial coherence of the first session was $A, 1.04 ; B 1,0.65 ; B 2$, $0.45 ; B 3,0.34$. Note the positive relationship between reproducibility and coherence. Median pixel rates $(\mathrm{Hz})$ are, for cell $A$ : $0,0.4,1.2,2.1,4.2,7.7$; cell B1: $0,0.6,1.5,2.3,3.4,5.5$; cell B2: 0 , $0.4,0.8,1.3,1.9,3.1$; cell $B 3: 0,0.8$, $1.5,2.3,3.7,7.1$. characteristic spatial period of MEC activity were about the same scale as the selected pixel size. At the same time, the reliability of the activity might be extremely high. It is therefore interesting that the correlation between coherence and reproducibility is substantial ( $r=0.74)$; the trend that leads to the high correlation is visible in the maps of Figure 4. Apparently, both coherence and reproducibility reflect the existence of a spatial signal.

The mean reproducibility for MEC cells was distinctly lower than the mean of $0.67 \pm 0.3 \mathrm{SD}$ for 33 hippocampal place cells $[t=10.4, p(t>10.4) \ll 0.001 ; \mathrm{df}=64]$. The higher variance in the MEC cells is clear from the appearance of the color-coded maps. It is important to note, however, that the hippocampal sample excluded place cells that happened to be virtually silent in the cylinder (see Muller and Kubie, 1987; Thompson and Best, 1989; Bostock et al., 1991) to make the two samples more comparable.

Long-duration recordings. If MEC cells show location-correlated firing whose period of spatial frequency is low compared to pixel size, the orderliness of the spatial firing pattern should improve with increased sampling time (Muller et al., 1987). Thus, if discharge is stationary and is a smooth function of 


\section{$12 \min$

A
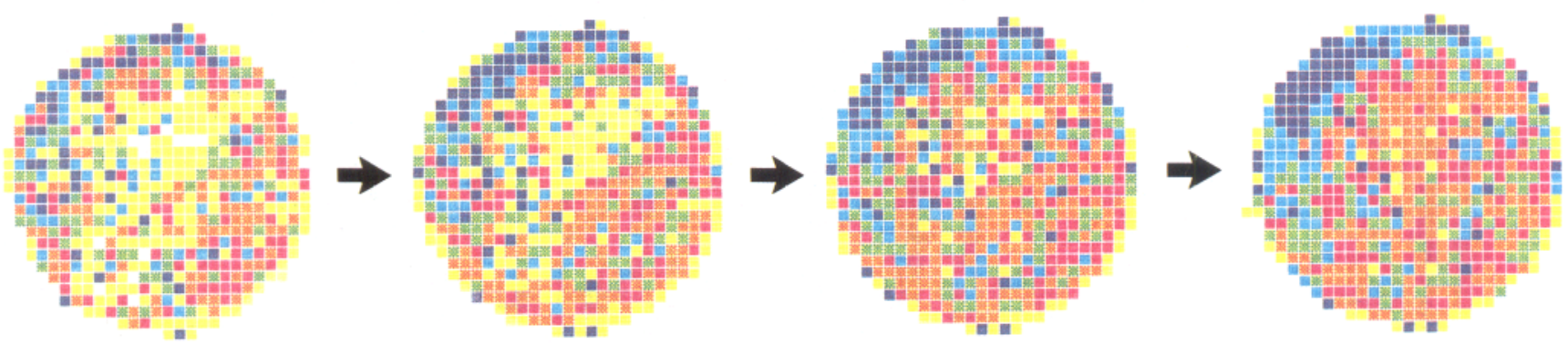

B
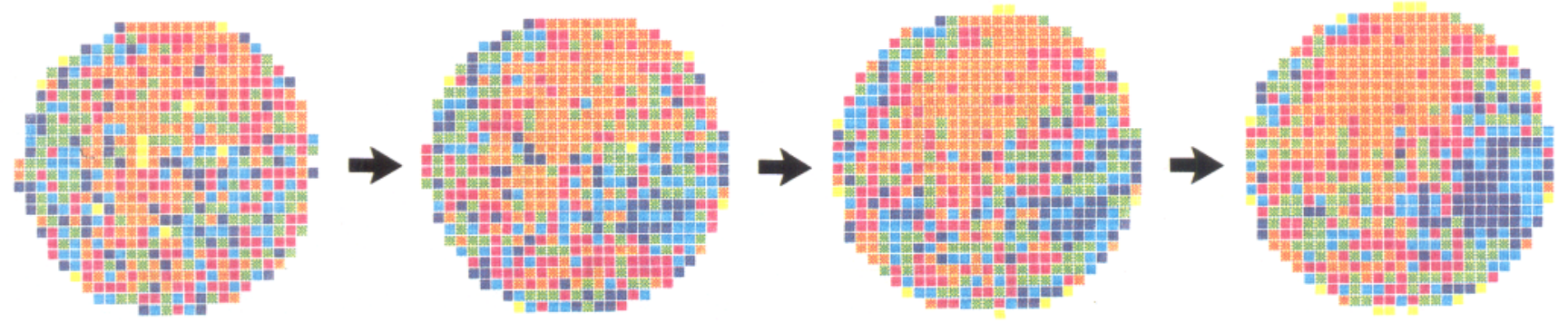

Figure 5. Rate maps showing the stationarity of firing patterns of two MEC cells. Consecutive 16 min recording sessions totaling 96 min were concatenated. Separate rate maps of the first 12, 24, 48, and $96 \mathrm{~min}$ are shown. Note the increase in orderliness of the spatial firing pattern. Coherence scores are, for cell $A: 0.33,0.40,0.42,0.43$; cell $B: 0.35,0.44,0.55,0.60$. Median pixel rates $(\mathrm{Hz})$ for 12 and 96 min maps are, for $A(12): 0,1.5,2.7,4.2,6.0,11.8 ; A(96): 0,0.4,0.8,1.3,2.0,3.2 ; B(12): 0,18.8,25.3,30.0,34.5,43.3 ; B(96): 0,21.4,25.2,27.5,29.9,32.8$ (the decrease in the averaged firing rate of cell $A$ was due to a slowing of the cell in the second, third, and fourth 24 min sessions).

location, coherence will increase with time. In contrast, coherence should approach zero (flat distribution) if firing is not location-correlated.

Multiple recording sessions from entorhinal cells were concatenated to produce long-duration firing rate maps. Figure 5 shows rate maps for two MEC cells after recording times of 12 , 24,48 , and $96 \mathrm{~min}$. What appears as a weak spatial signal at $12 \mathrm{~min}$ emerges as a strong signal at $96 \mathrm{~min}$. This is evident from inspection of the maps and from the coherence scores given in the Figure 5 caption.

To examine this trend more closely, coherence was plotted as a function of sampling time from 1 to $64 \mathrm{~min}$ in $1 \mathrm{~min}$ increments for eight hippocampal place and eight MEC cells (Fig. 6, left). After $64 \mathrm{~min}$ of recording, the mean coherence values were $1.48 \pm 0.4 \mathrm{SD}$ and $0.72 \pm 0.3$ for hippocampal place cells and MEC cells, respectively. More importantly, the plot of coherence verses sampling time makes it clear that the coherence of MEC cells continues to grow even when the average sampling time per pixel approaches $8 \mathrm{sec}$. It remains an open question whether the coherence of MEC firing patterns would reach that of hippocampal cells, given enough time. A similar calculation was performed for four hippocampal theta cells, which have been shown to generate a location-specific signal (Kubie et al., 1990). The bar graph of Figure 6 (right) shows that the coherence of theta cells after 64 min of recording reaches a value (0.88) midway between those for place and MEC cells.

The flat line in Figure 6 (MEC-RANDOM) is included to show that the coherence of spatially random firing is zero, independent of sampling time. The values for this line were obtained by randomizing the pixel firing rates associated with MEC cells after each minute of recording. The coherence values of zero after randomization provide evidence that coherence is a valid way of distinguishing between location-correlated and location-independent firing.

\section{The role of the rat's behavior in generating entorhinal firing patterns}

The stationarity of entorhinal firing patterns is evidence that MEC cell discharge is location-correlated. As stated above, however, there are several possible sources of location-correlation in addition to location itself. We first consider behavior-specific firing, in which activity occurs in association with certain acts that are themselves inhomogeneously distributed in space. Several lines of evidence will be offered to show that the behavior of the rat is not a critical factor in generating the observed firing patterns.

First, as noted above, we saw no obvious tendency of spikes to occur preferentially or to be suppressed during eating, grooming, quiet alertness, or rearing, which are the only nonlocomotor activities seen during pellet chasing. During pellet chasing, rats are observed to spend at least $85 \%$ of the time walking or running and the remaining time in other states (Bostock et al., 1991).

An additional indication that location-correlated firing is not 


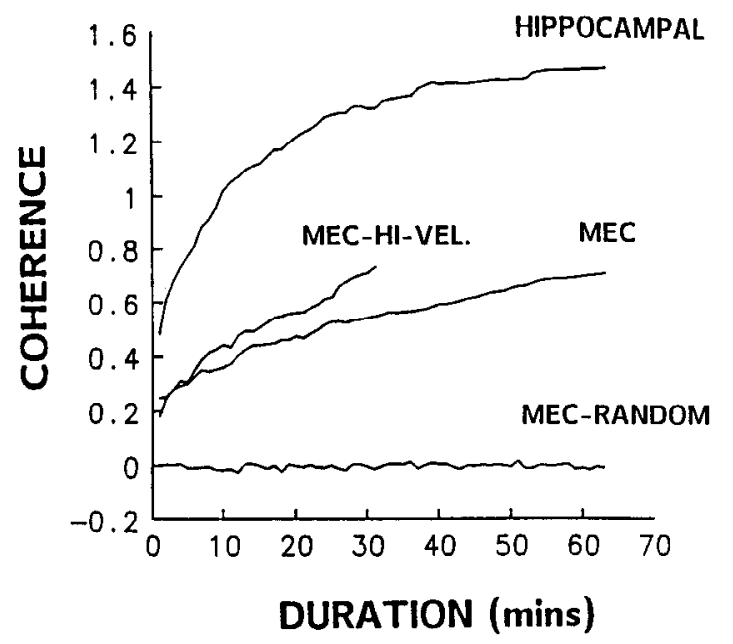

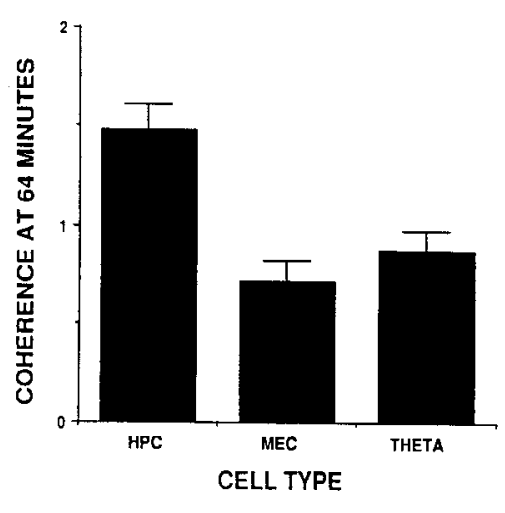

Figure 6. The effect of sampling time on spatial coherence of firing patterns. Left, The average spatial coherence verses time is plotted for groups of MEC cells, hippocampal place cells, and randomized-MEC cells, from 0 to $64 \mathrm{~min}$. Right, Histogram of final coherence values for MEC cells $(n=8)$, hippocampal place cells $(H P L ; n=8)$, and hippocampal theta cells $(n=4)$. Error bars indicate one $\mathrm{SE}$. simply behavior-correlated firing arises from a method that further reduces behavioral variations. In this method, data from recording sessions were sorted according to the locomotor speed of the rat. Samples were selected if the rat moved at least 10 $\mathrm{cm} / \mathrm{sec}$ averaged over intervals of $0.25 \mathrm{sec}$ (15 samples); this selection eliminated about half the samples for each session, leaving behind only "high-velocity" samples.

Rather than reduce spatial selectivity, speed selection actually enhanced the spatial signal of MEC cells (compare the lines labeled MEC and MEC-HI-VEL. in Fig. 6). Because coherence increases after speed selection, we conclude that the spatial signal of MEC cells cannot be explained by variations in the rate of locomotion. In addition, because a rat moving at high speed must be locomoting, it is implausible that modulations associated with nonlocomotor activities or with switches from nonlocomotor to locomotor activities are responsible for the spatial firing pattcrns of MEC cclls.

Another possible behavioral predictor of spatial firing patterns is the tendency of the rat to spend more time in certain portions of the apparatus than in others. If location-correlated firing reflects the rat's preference for certain regions, the correlation between firing rate and dwell time should be positive across cells; similarly, a mean negative correlation would occur if firing were associated with regions that are to some extent avoided. As was true of hippocampal place cells (Muller et al., 1987), the rate/dwell-time correlation was positive for a few MEC cells, negative for a few others, and indistinguishable from zero for most cells. For both cell classes, the mean correlation was not different from zero $[r=-0.004$ for 55 MEC cells; $t=$ $0.34 ; p(t>0.34)=0.37]$. It therefore seems that the spatial representation in the MEC cell population is independent of regional preferences.

We conclude that there is no evidence that the rat's behavioral state is a major determinant of the location-correlated firing of MEC cells. We now turn to several issues that bear directly on the nature of the environmental representation.

\section{The cue card has stimulus control over the spatial firing of $M E C$ cells}

Muller and Kubie (1987) showed that the white cue card inside the cylinder controls the angular position of place cell firing fields; rotations of the card cause equal rotations of firing fields. Despite the almost ideal control of positional firing by the card, removing the card docs not causc major changes in firing ficlds. Specifically, the shape, size, intensity, and radial position of fields are unaffected by card removal. The major effect of card removal is to cause unpredictable rotations of otherwise unchanged fields (Muller and Kubie, 1987). The preserved positional firing patterns after removal of the only salient angular cue is taken as evidence that place cells are not well described in simple sensory terms. The same conclusion was reached for head-direction cells in the postsubiculum after card rotation and card removal manipulations (Taube et al., 1990b).

MEC cells respond similarly to both place cells and headdirection cells after card rotation and removal. Fifteen MEC cells were tested with card rotation. Between recording sessions, the card was detached from the wall and reattached in the new position and floor paper was changed; the cylinder itself was never rotated. Figure 7 shows examples of card rotation for two MEC cells in the cylinder. In each case, it is clear that the firing pattern follows the card position. The accuracy with which firing patterns followed card positions was measured by calculating the cross-correlation between the rotated and unrotated firing patterns as the one pattern is displaced relative to the other in $6^{\circ}$ steps (Muller and Kubie, 1987). The angle associated with the maximum similarity estimates the observed rotation. The error of rotation was obtained by subtracting the observed rotation from the card rotation. Data from the MEC cells were compared with 25 place cells similarly tested.

Figure 8, $A$ and $B$, shows plots of the cross-corellation verses angular displacement for representative entorhinal and hippocampal cells. To obtain a more reliable estimate of the rotational error for MEC cells, the cross-correlations were smoothed by taking a running average over five angular displacement bins $\left(30^{\circ}\right)$. Histograms of the rotational error for MEC and place cells are displayed in Figure 9, $B$ and $D$. Despite the large variance in the rotational error for MEC cells, a Rayleigh test revealed a significant grouping of the observed angles of rotation close to the expected value of $0^{\circ}$ (mean angle, $18^{\circ}$; Rayleigh vector, $0.54 ; n=15 ; p<0.05)$. The magnitude of the error, however, was much less for place cells, as evidenced by a higher variance in the entorhinal group compared to the hippocampal group [ $F$ $-26 ; p(F>26) \ll 0.001]$. Thus, the firing patterns of the entorhinal cells rotated with the cue card, but with greater error than hippocampal place cells.

The much larger error variance for MEC cells may have been 

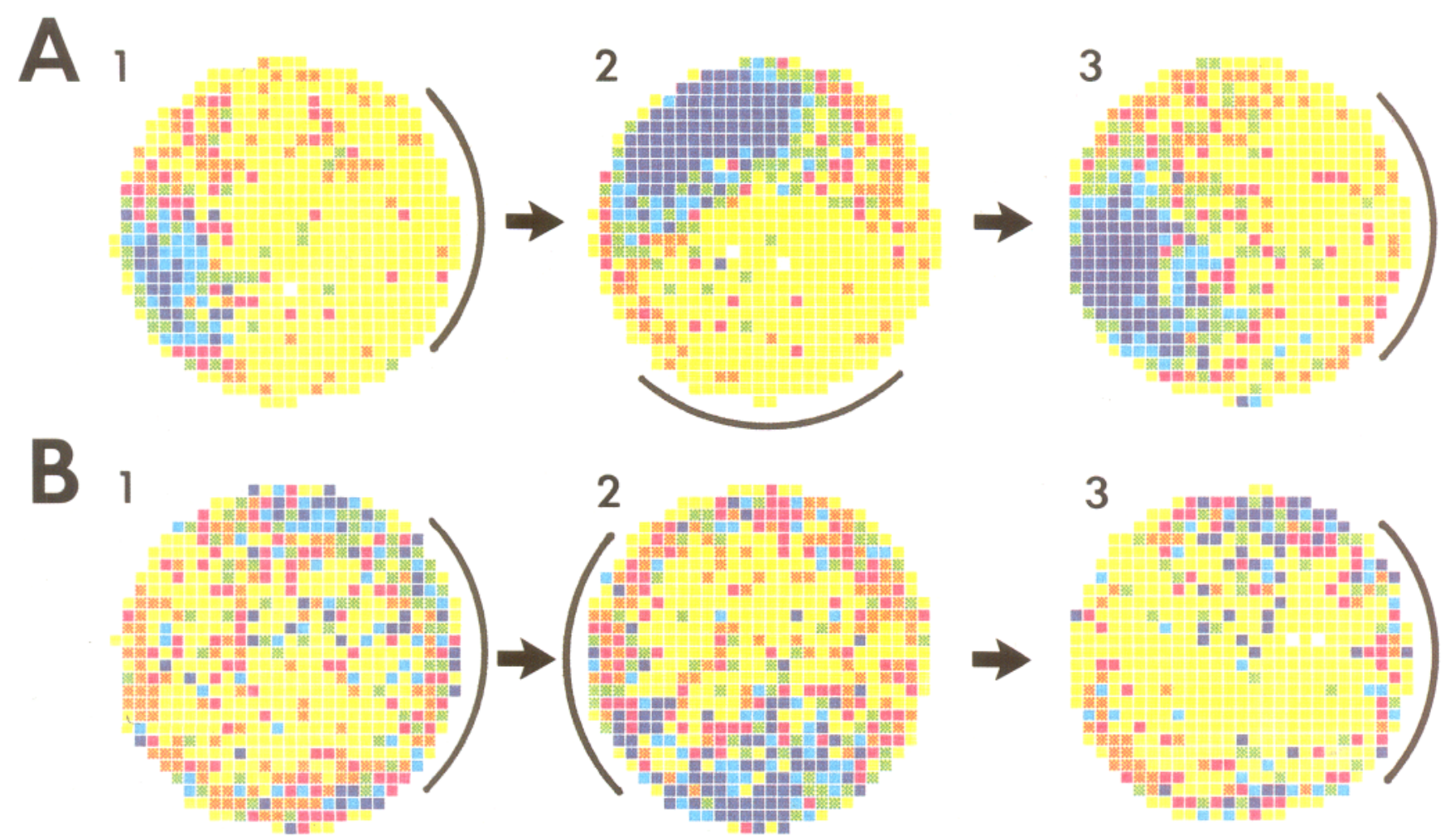

Figure 7. Cue card control of the spatial firing patterns in two MEC cells. Between recording sessions 1 and 2, the cue card was rotated from its standard position in the cylinder at 3:00 to 6:00 in cell $A$, and 9:00 in cell $B$. Notice that the MEC firing patterns follow the cue card. The value of the angular cross-correlation between rotated and unrotated sessions was maximal at $276^{\circ}$ for cell $A(0.93)$, and $186^{\circ}$ for cell $B(0.58)$. Median pixel rates $(\mathrm{Hz})$ were, for cell $A$ : $0,0.7,1.8,3.8,8.1,14.0 ;$ cell $B: 0,0.7,1.4,2.2,3.0,4.5$.

due to the poor reproducibility of the relatively weak spatial signal of MEC cells rather than to inaccurate following of the card per se. To dissociate these two factors, the angular error from rotation experiments was compared to the angular error of 32 replication experiments, where there was no change in the position of the card. In hippocampal cells, the variance in rotational error is greater for rotations than replications (Muller and Kubie, 1987), suggesting that cues other than the card play a role in controlling the angular position of firing patterns. As seen in the error histograms of Figure 9, MEC cells share this property with hippocampal cells. The error in rotation experiments is greater than the error in replication experiments $[F=$ $3.6 ; p(F>3.6)<0.01]$. Thus, the majority of error observed in entorhinal rotations does not arise from low reproducibility, but a failure of entorhinal cells to follow the card completely. As with hippocampal cells, factors other than the card determine the angular position of entorhinal firing patterns.

The effects of card removal were observed in four entorhinal cells, and in all cases spatial firing was still present in the absence of the card. In two cells, card removal had little effect on the firing pattern, whereas the other two changed more dramatically. Figure 10 shows the two examples of persistence of spatial firing pattern following card removal. Entorhinal firing patterns with and without the card were not different with respect to spatial coherence (card, 0.289; no card, 0.386; df $=6 ; t=-1.11 ; p=$ 0.15 ) or average firing rate (card, 13.74; no card, 13.67; $\mathrm{df}=6$; $t=0.01 ; p=0.49$ ). These four cells provide preliminary evidence that, like hippocampal place cells, the firing patterns of entorhinal cells can be controlled by the card but do not require the card.

\section{Spatial distribution of MEC firing patterns in the cylinder}

There was no tendency across hippocampal place cells for firing fields to cluster in any part of the cylinder (Muller et al., 1987), implying that floor area is represented homogeneously by the population. A similar analysis was performed for 53 MEC cells recorded in the cylinder. The center of the spatial firing pattern was defined as the central pixel of the $3 \times 3$ pixel area with the highest overall firing rate. To test for angular clustering, the cylinder was divided into eight $45^{\circ}$ sectors. According to a $\chi^{2}$ test, the observed number of centers in each sector did not differ from the expected number $\left(\mathrm{df}=7 ; \chi^{2}=6.6 ; p=0.47\right)$. Thus, in common with place cells, there is no tendency for MEC cell spatial firing pattern centers to occur preferentially near the white cue card. Similarly, no clustering was found among four equal-area concentric annuli $\left(\mathrm{df}=3 ; \chi^{2}=5.2 ; p=0.16\right)$, ruling out a strong tendency for maximal firing to occur near or away from the cylinder walls.

In the hippocampus, there is little tendency for neighboring place cells to have firing fields that overlap or are near each other, indicating that space is not topographically mapped onto the surface of the hippocampus (O'Keefe, 1976; Muller et al., 1987). In three cases, it was possible to record simultaneously from two MEC cells whose waveforms appeared on the same electrode. An estimate of the maximum distance between two cells recorded with a $25 \mu$ m electrode is $100 \mu \mathrm{m}$ (Fox and Ranck, 
A

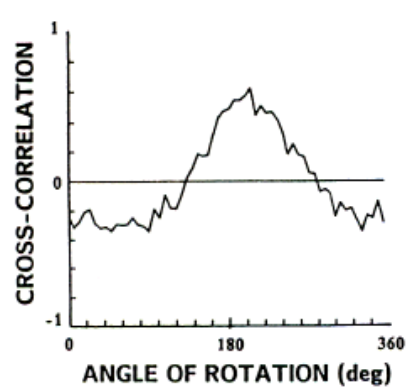

B

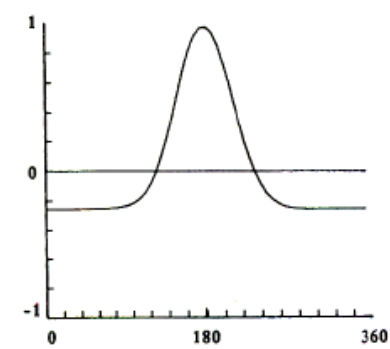

Figure 8. The angular cross-correlation between rotated and unrotated recording sessions is plotted verses the angle of rotation, for representative entorhinal $(A)$ and hippocampal $(B)$ cells. The maximum correlation occurred at or close to $180^{\circ}$, which was the extent of card rotation.

1975), which is on the order of the width of an isocortical column. The spatial firing distributions of cells in all three pairs bore little resemblance to each other. Thus, as in hippocampus, we find no evidence of topographic mapping of space onto the entorhinal cortical sheet.

\section{Changing the shape of the chamber causes topological transformations of MEC firing patterns}

When recorded in both the cylinder and a rectangular chamber, place cells are virtually silent in one or both apparatuses or display fields in the two apparatuses that are unrelated to each other (Muller and Kubie, 1987). This is remarkable because the sensory input to the rat is so similar in the rectangle and cylinder: the walls are of equal height and gray in color, the white card covers $1 / 4$ of the perimeter, and the floor and extraapparatus cues are identical. It seems, therefore, that individual place cells fire only in a fraction of the environments that are familiar to the rat and that firing patterns in one environment cannot be predicted from firing patterns in other environments (see also Kubie and Ranck, 1984; Thompson and Best, 1989; Bostock et al., 1991). We tested whether MEC cells share with place cells the property of undergoing unpredictable changes in spatial firing pattern between two differently shaped chambers by recording in the cylinder and a square apparatus of equal area to the cylinder. In order to compare entorhinal cells directly to hippocampal cells (where a rectangle rather than a square was previously used), the same experiment was performed on a new sample of hippocampal place cells.

Sixteen MEC cells and 18 hippocampal place cells were recorded for $16 \mathrm{~min}$ in the cylinder and square. On the whole, entorhinal firing patterns appeared more similar between cylinder and square than did hippocampal cells. Figure 11 shows rate maps for the shape change experiment for four representative MEC and hippocampal cells. One obvious difference between the responses of the two cell types to shape change was that none of the MEC cells were silent in either chamber, whereas four place cells (from four rats) were silent in one of the chambers. In addition, from visual inspection, the degree of location-specificity and often the location of the highest firing rate region relative to the card were similar in the two chambers for MEC cells, but not hippocampal place cells.

Numerical methods were used to compare the effects of changing apparatus shape on the spatial firing distributions of MEC and place cells. The results are shown in the bar graphs of Figure

ENTORHINAL CELLS
A

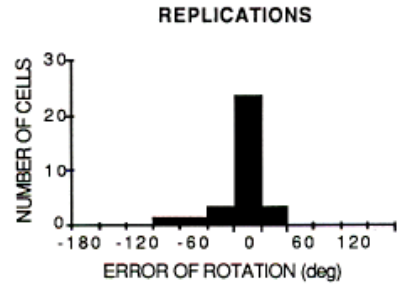

HIPPOCAMPAL CELLS

C

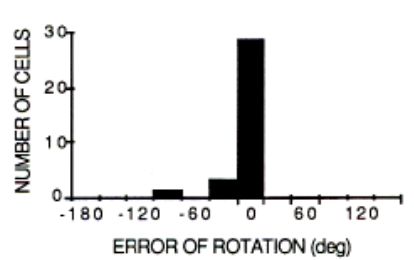

B

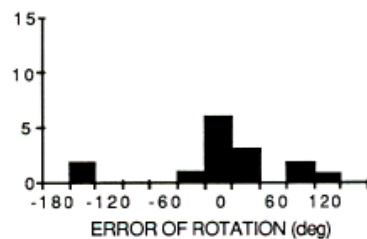

ROTATIONS

D

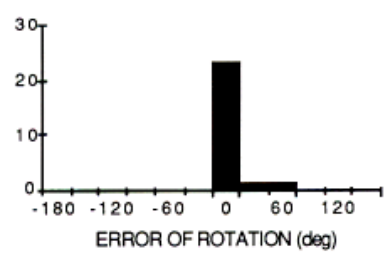

Figure 9. The rotational error derived from the angular cross-correlation between card-rotation sessions $(B, D)$, and replication sessions where the position of the card was not changed $(A, C)$, for entorhinal and hippocampal cells. The position of the center of the cue card is defined as $0^{\circ}$ in all plots.

12. First, the correlation was calculated between the overall firing rate in the square and cylinder. The correlation was 0.97 for MEC cells and 0.10 for place cells. Thus, the shape change hardly influenced the firing rate for MEC cells. In contrast, the overall rate for place cells in one chamber did not predict the overall rate in the other.

The second kind of comparison concerned the effects of ap-

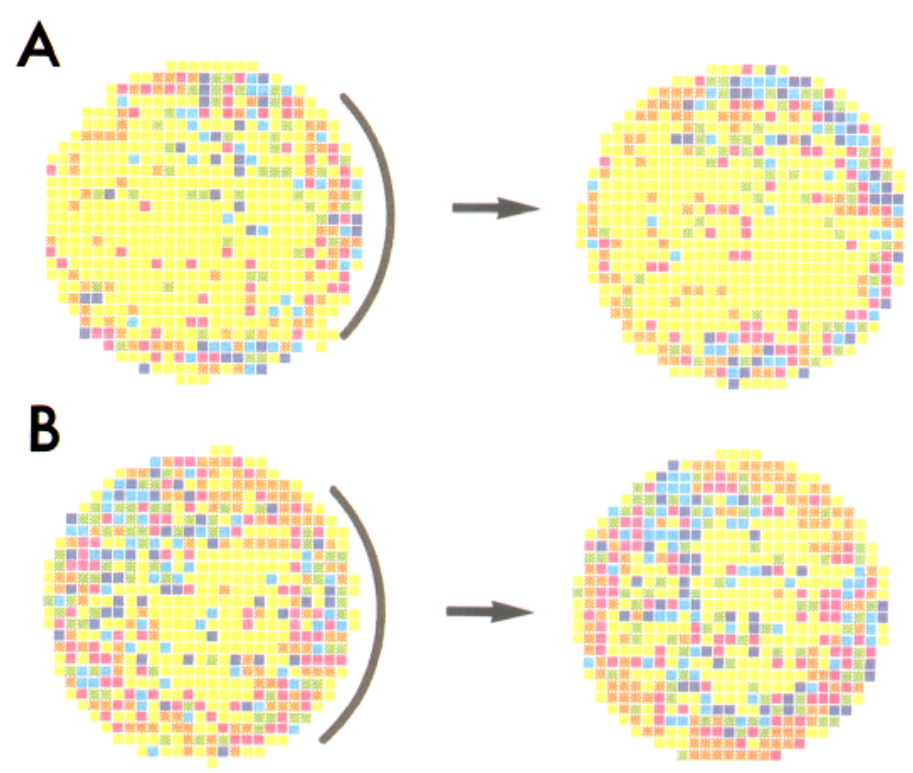

Figure 10. Two examples of removing the cue card in MEC cells. In both cases, the firing pattern was largely unaffected. Median pixel rates $(\mathrm{Hz})$ were, for cell $A: 0,0.5,0.9,1.4,2.1,3.5$; cell $B: 0,0.7,1.4,2.1$, 2.8, 4.3. Cross-correlations between card and no-card sessions were, for cell $A, 0.112$, and cell $B, 0.062$ (average for MEC replications, 0.12). 

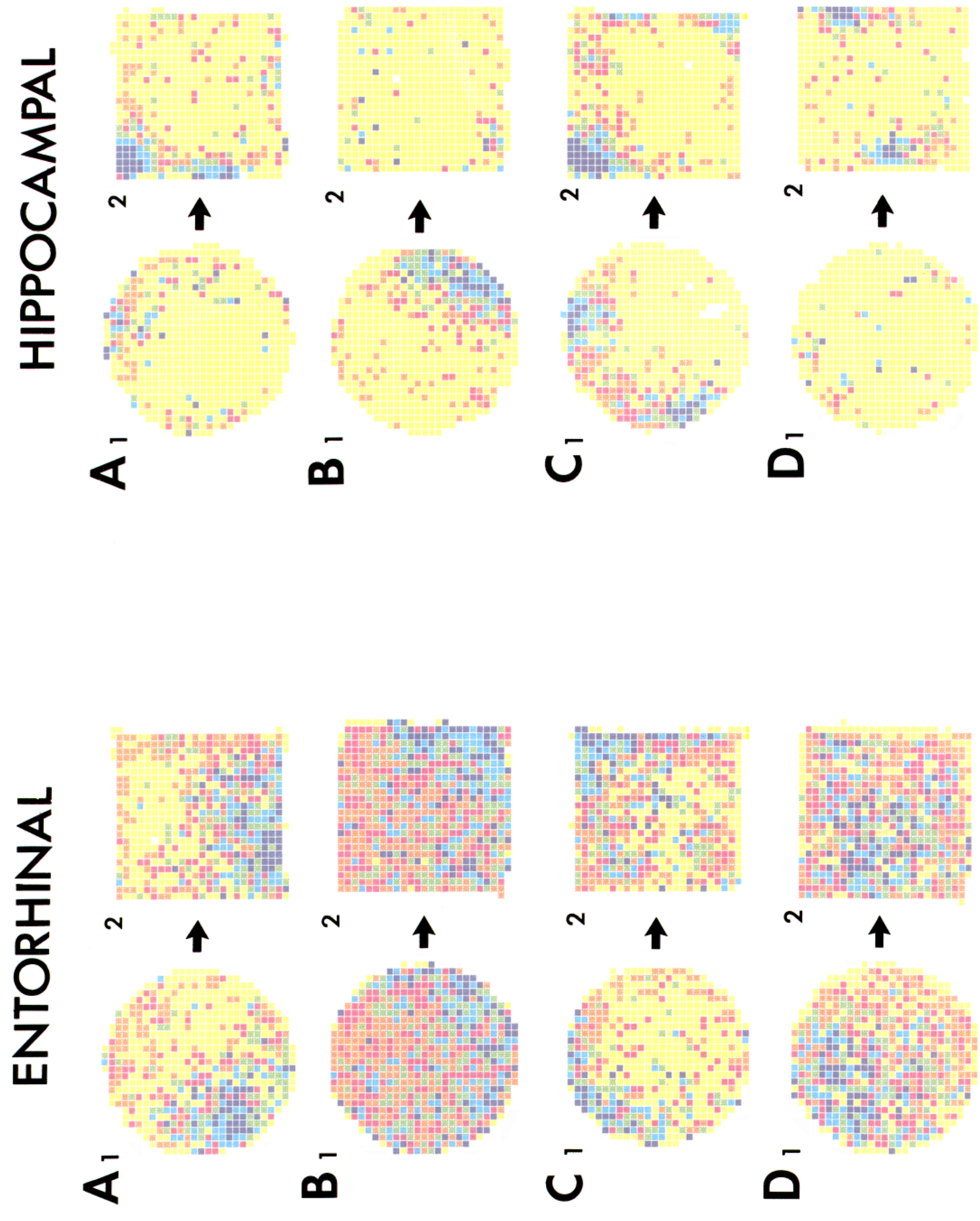

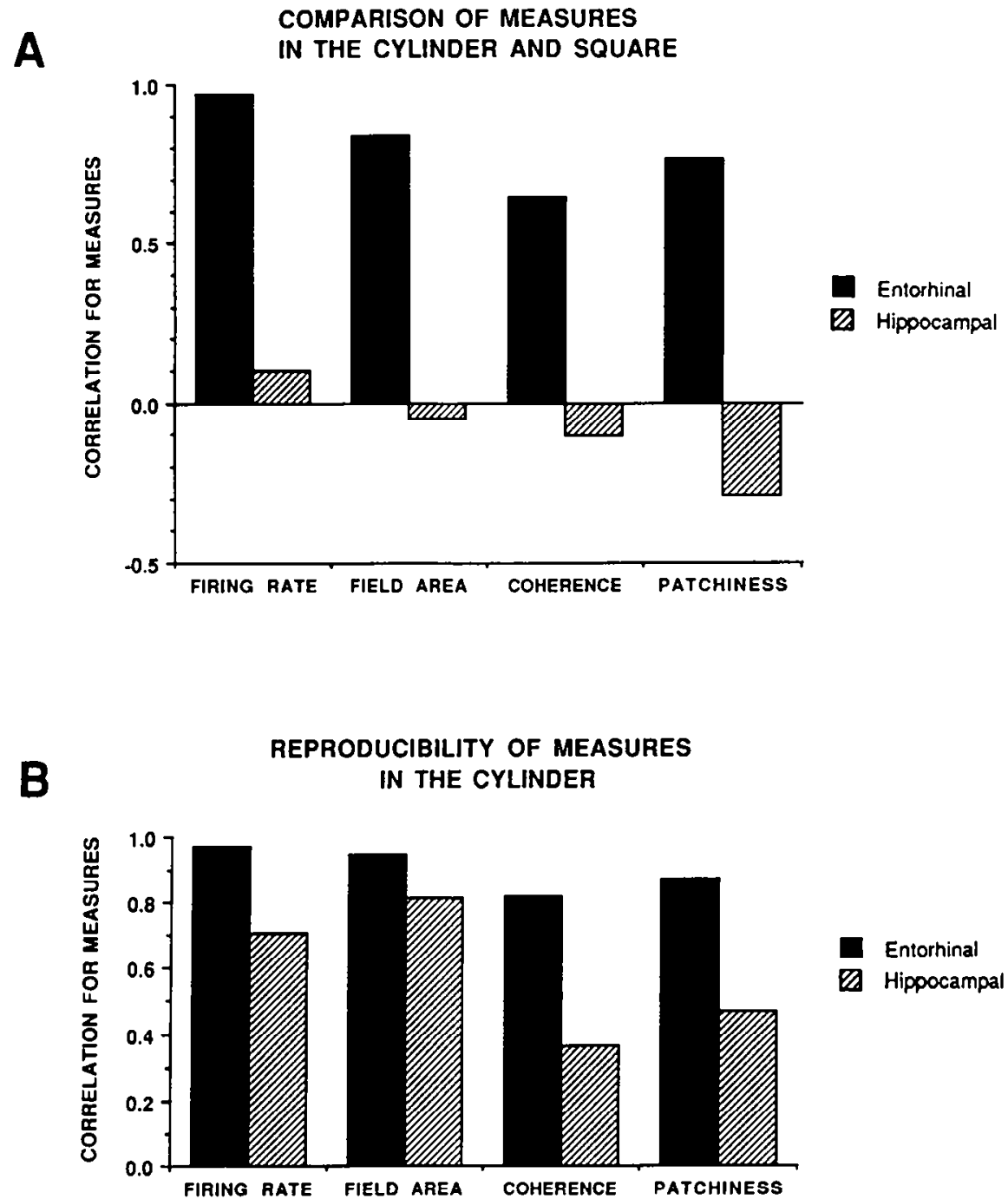

Figure 12. Comparison of firing patterns in the cylinder and square with respect to time-averaged firing rate, and three measures of the "orderliness" of firing patterns (spatial coherence, firing area, and number of high-rate patches). The bars indicate the value of the correlation, between each measure (firing rate, field area, coherence, and patchiness), for the cylinder and square firing patterns $(A)$, and a cylinder-cylinder replication $(B)$ for 16 MEC cells (solid bars) and 18 hippocampal place cells (hatched bars).

paratus shape on the orderliness of spatial firing patterns; the three measures of orderliness (Muller and Kubie, 1989) yiclded similar results. Firing area (the number of pixels with firing rate greater than zero) estimates the degree to which firing is localized. The correlation for firing area in the cylinder and square was 0.84 for MEC cells and -0.05 for place cells. The corrclation between coherence scores in the cylinder and square was 0.64 for MEC cells and -0.10 for place cells. "Patchiness," the number of continuous high rate regions, estimates the large scale orderliness of firing patterns. The correlation between patchiness scores in the cylinder and square was 0.77 for MEC cells and
-0.29 for place cells. In each case, it appears that the firing pattern is preserved for MEC cells but not for place cells after shape change.

To test if the low correlations for place cells are due to intrinsic instability of spatial firing patterns, Pearson correlations for overall firing rate, firing area, coherence, and patchiness were calculated for pairs of sessions done in the cylinder. For such replication pairs, all correlations for both cell types were high. Bar graphs of correlations for cylinder/cylinder comparisons are shown next to cylinder/square comparisons in Figure 12. Low correlations were found only for place cells after shape

Figure 11. Comparison of firing patterns in the cylinder and square for four MEC cells (left) and four hippocampal place cells (right). Note the markcd degrec of similarity between cylinder and square firing patterns in MEC, but not hippocampal place cells, in terms of the degree of spatial "orderliness" and the location of high-rate regions relative to the cue card. Average firing rate and spatial coherence for the sessions were as follows:

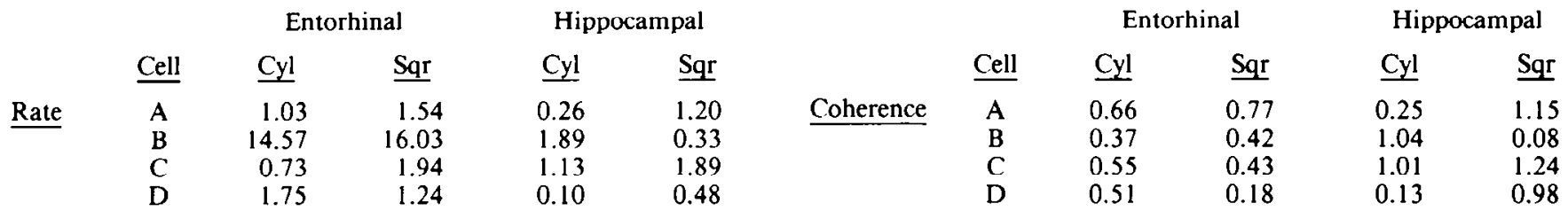



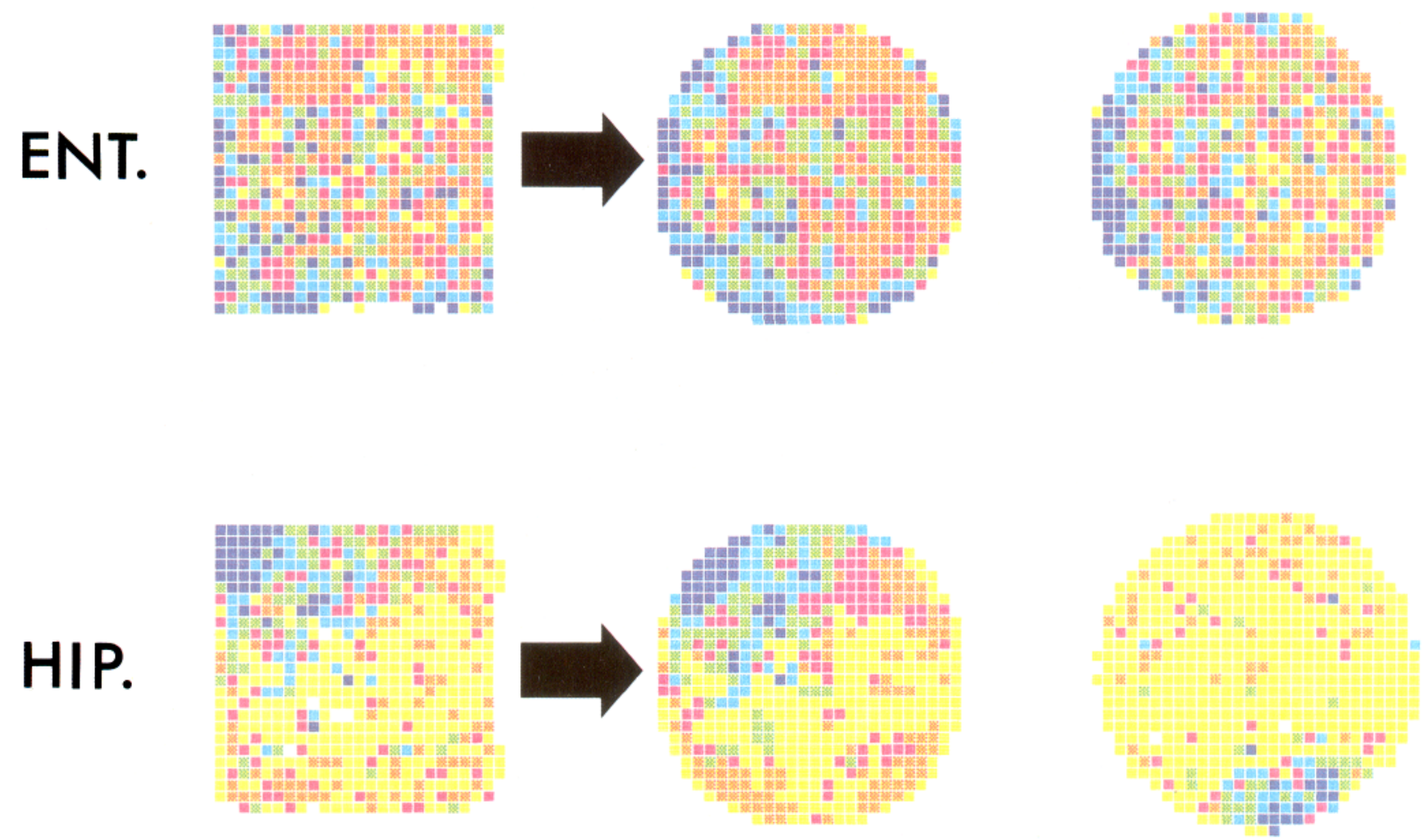

Figure 13. Examples of the stretching procedure used to transform square firing patterns topologically to circular firing patterns shown for an MEC cell (top) and a hippocampal place cell (bottom). The center map in each row is the square firing pattern following compression into a circular firing pattern. On the far right is the actual cylinder recording session. Note the similarity between the transformed square and cylinder patterns for the MEC cell, but not the place cell. The rotational cross-correlation between the transformed square and cylinder was maximal at $-6^{\circ}(0.46)$ for the entorhinal cell and $-150^{\circ}(0.71)$ for the hippocampal cell.

change, indicating that shape change had a specific effect on place cells but not MEC cells.

As suggested above, visual comparisons of color-coded rate maps for cylinder and square sessions give the impression that the firing patterns of MEC cells in the two chambers are topological transforms of each other, such that the transformation mimics the topological distortion that carries the cylinder into the square. This hypothesis is plausible in that the visual appearance of the two chambers (gray wall with a single white cue card) are extremely similar except for shape. To test this hypothesis, spatial firing distributions from square chamber sessions were topologically distorted so as to create circular firing patterns (see Materials and Methods for algorithm). Examples of the original square pattern, the transformed pattern, and the corresponding cylinder are shown in Figure 13 for an MEC cell and a place cell. Two points should be made about these data. First, it was much less common for the transformed square and cylinder maps to be superimposable for place cells than for MEC cells, an outcome that is predictable from the raw cylinder and square maps shown in Figure 11. Second, it appears that the amount of rotation needed optimally to superimpose the transformed and cylinder patterns is less for the MEC cell than for the place cell. This is a critical observation, since the hypothesis that the square pattern is a topological distortion of the cylinder pattern implies that the two patterns should be at the same angular position relative to the cue cards, which are known to control the angular position of firing patterns.
Accordingly, we calculated the amount of rotation needed optimally to superimpose the transformed square firing pattern on the cylinder pattern by calculating the cross-correlation on a pixel-by-pixel basis as one pattern is rotated against the other in $3^{\circ}$ steps. For each cell, the angle that maximized the crosscorrelation was determined. If cylinder and square firing patterns are topological transforms of one another, the maximal cross-correlation would be expected to occur close to $0^{\circ}$ rotation. Figure 14 shows representative plots of the cross-correlation verses angle of rotation for three entorhinal and three hippocampal cells. MEC cell maxima tended to occur close to $0^{\circ}$, whereas place cell maxima were scattered. The histograms of Figure 15 show the angle of maximum correlation for all cells in entorhinal and hippocampal samples. The proportion of cells whose optimal angle occurred within $\pm 60^{\circ}$ of zero was 5 of 17 for hippocampus, and 11 of 16 for entorhinal cortex. The binomial probability of achieving these proportions by chance was expected for hippocampal cells $(p=0.65)$ but highly unlikely for entorhinal cells $(p=0.004)$. In addition, a Rayleigh test for randomness showed significant clustering of angles of entorhinal cells $(r=0.46 ; p<0.05)$ but not hippocampal cells $(r=0.28$; $p=0.27$ ). This is strong evidence that, unlike hippocampal cells, firing patterns of most entorhinal cells in cylinder and square chambers are topological transforms, or "stretched" versions of one another. This is an important difference from hippocampal cells, whose firing patterns in the cylinder and square are unrelated (Muller and Kubie, 1987). 


\section{ENTORHINAL}
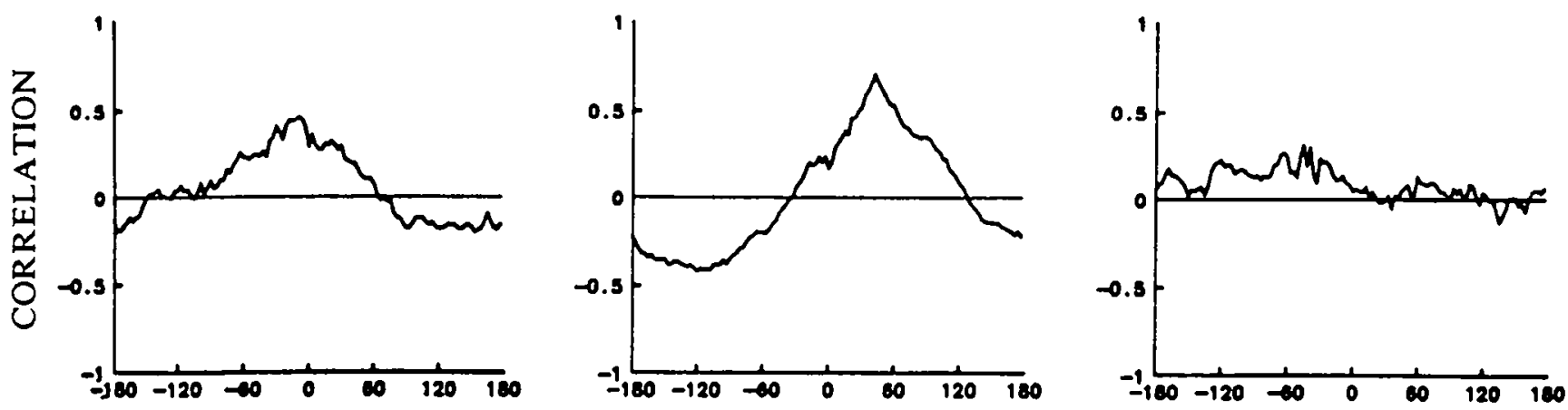

\section{HIPPOCAMPAL}
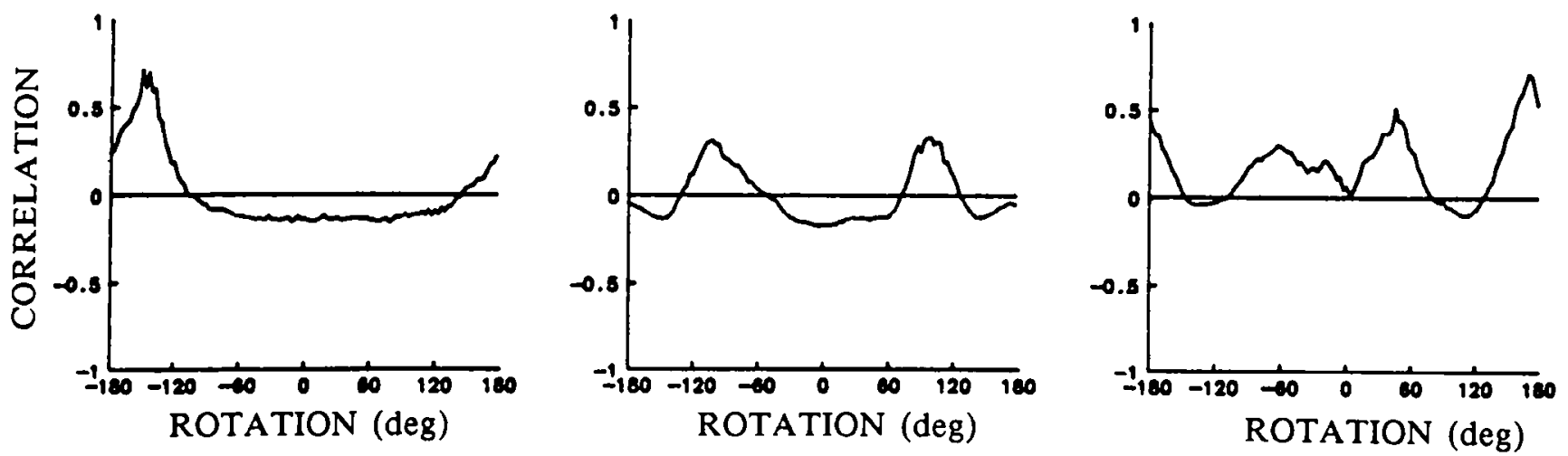

Figure 14. The results of the rotational cross-corrclation between cylinder and square firing patterns for three representative MEC (top) and hippocampal place cells (bottom). The far left plots correspond to the cells whose rate maps are shown in Figure 13. In MEC cells, the peak correlation was obtained close to $0^{\circ}$ rotation, while no such tendency was observed in hippocampal cells.

\section{Discussion}

We have investigated the positional firing properties of cells in superficial layers of MEC. Our description of MEC cells is done in terms of comparisons with hippocampal place cells, a process that is possible because MEC cells were investigated under the same conditions used in earlier work on place cells. Hippocampal and entorhinal cells can be compared at three distinct levels. Comparisons at the first level are strictly phenomenological; they in no way depend on the fact that MEC and place cells are interconnected and can be made without assuming that firing in one region is a determinant of firing in the other.

At a second level, it is possible to treat the firing of hippocampal place cells as a transform of the firing of MEC cells. This view focuses on the fact that cells in superficial MEC are afferent to Ammon's horn, but ignores other important anatomical features of the hippocampal area. In the second section of the Discussion, we will show that even such a limited analysis leads to interesting conclusions.

At the third level, the results can be considcred in terms of the ensemble activity of the MEC and place cell populations. It is only at this level that the question of the neural representation of the environment is raised. In this section of the Discussion, emphasis is put on the ability of the place cell population to reflect differences among environments, in addition to the abil- ity that it shares with the MEC cell population of signaling position within the current environment.

\section{Phenomenological comparisons of the properties of $M E C$ and place cells}

$M E C$ cells show location-correlated firing. When place cells are recorded in a variety of circumstances, including the "standard" cylinder, the locations of their firing fields are apparent from direct observation (see Best and Ranck, 1984). In contrast, for most MEC cells it is difficult if not impossible to distinguish regions of high and low firing rate by listening to acceptance pulses from discriminators while watching the rat. The basis of this difference is the weaker correlation between cell discharge and position for MEC cells. They tend to fire at appreciable rates throughout the recording chamber, so that the contrast between high and low rate regions is much less than for place cells.

Vidco tracking of the rat's position and the firing rate showed that most MEC cells generate appreciable spatial firing variations. The average spatial coherence for MEC cells after $16 \mathrm{~min}$ of recording was 0.38 and was normally distributed in the sample. As expected from direct observation, the degree of locationcorrclation revealed by numerical methods is considerably lower for MEC cells than for hippocampal place cells. MEC firing 

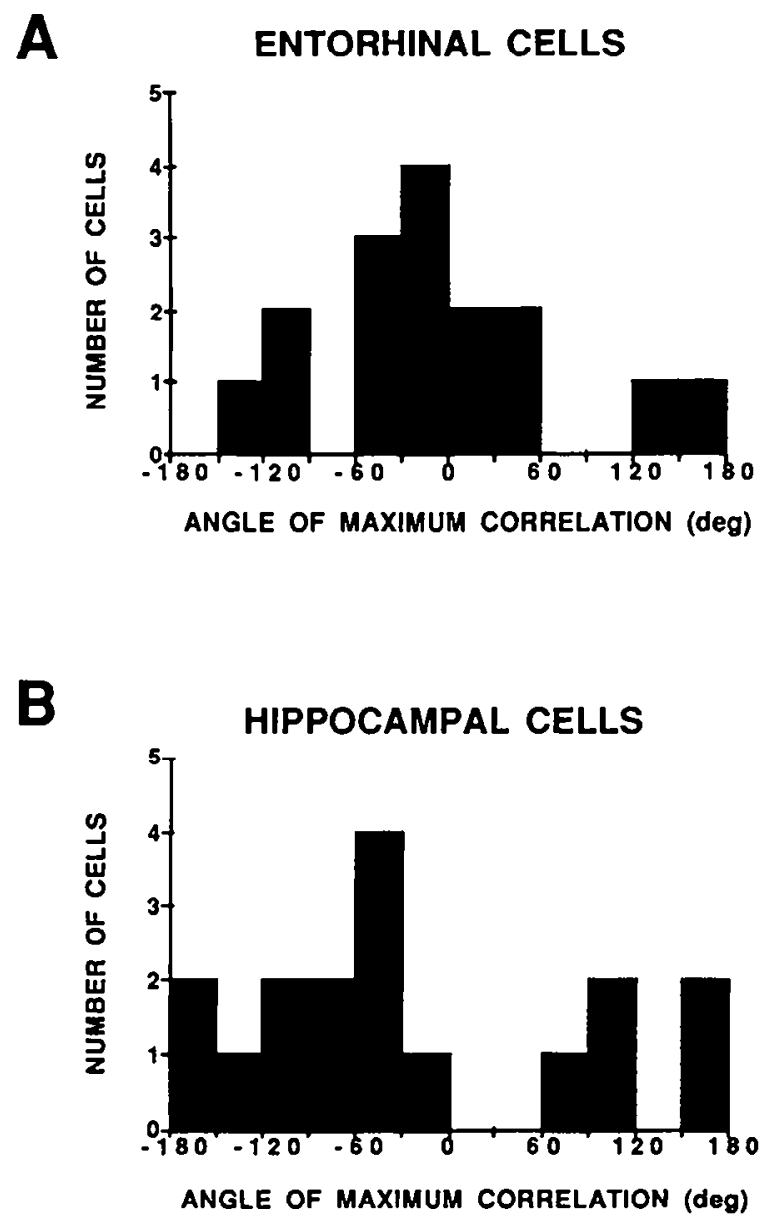

Figure 15. The angle of rotation at which the maximal cross-correlation between cylinder and square firing patterns was observed for MEC cells $(n=16)$ and hippocampal place cells $(n=17)$. Note the clustering of entorhinal cells, but not hippocampal cells, close to $0^{\circ}$.

patterns were usually characterized by diffuse firing throughout the chamber with a single region of higher-than-background firing rate. The contrast between high and low rate regions is so low, however, that we reserve the term "firing fields" for hippocampal place cells where almost all the firing is confined to a restricted arca. On a smaller scale, the local discharge contours of MEC cells are noisier, so that small movements do not yield reliable differences in time-averaged rate until the recording time is much longer than for place cells. The positional firing of MEC cells is reproducible, and the local orderliness (measured by coherence) of the patterns grows with increasing recording time. The reproducibility and the growth of coherence are taken as evidence that the positional patterns are stationary, so that MEC cell firing is properly described as location-correlated.

$M E C$ cell discharge is behavior independent and has a complex relationship to sensory cues. In previous work, we have argued that location per se is the best available descriptor of place cell firing in the hippocampus. This was based on showing (1) the positional firing of place cells is not primarily correlated with behavioral variables, and (2) the relationship between place cell firing and sensory cues is not simple (e.g., card removal does not affect firing). Several lines of evidence were offered in the present study to show that the positional firing of MEC cells is also not primarily behavior-correlated. First, the pellet chasing task is specifically designed to reduce behavioral variation, and a numerical analysis has shown that nonlocomotor activities are too infrequent to account for much positional firing variance (Bostock et al., 1991). Second, several recordings were made while MEC spike/position samples were tagged according to ongoing behavior. No tendency was found for spikes to occur preferentially during three of the most common nonlocomotor activities (still-alertness, grooming, and rearing) emitted during pellet chasing. Third, coherence was calculated for intervals during which the rat moved at a speed higher than a selected cutoff. Although speed selection further restricts the possible behavioral state of the rat, coherence increased, an outcome at odds with the notion that MEC cell firing is behavior correlated. Finally, as was true for place cells, but not for theta cells (Kubie et al., 1990), there was no tendency of MEC cells to show reduced or excess discharge in regions where the rat spent more timc. We conclude that there is no strong connection between MEC cell firing and the concurrent behavior of alert rats.

With respect to sensory cues, previous work on hippocampal cells has suggested that spatial firing is not well described in simple sensory terms, such that each cell is triggered by the conjunction of a set of stimuli to which the cell is tuned. Muller and Kubie (1987) showed that rotations of the white cue card produced equal rotations of place cell firing fields. Despite the almost ideal control exerted by the white card, removing it from the cylinder left firing fields intact with regard to shape, size, and radial distance from the cylinder center; only the angular position of fields relative to the laboratory frame changed. The same observation has been made for hippocampal theta cells (Kubie et al., 1990), head direction cells in the postsubiculum (Taube et al., 1990b), and subicular units (Sharp et al., 1990b). Several other stimulus manipulations reinforce the conclusion that place cell firing is not triggered by immediately present cues in the fashion expected of sensory units (O'Keefe and Conway, 1978; O'Keefe and Speakman, 1987; Muller and Kubie, 1989; Quirk et al., 1990; Sharp et al., 1990a).

In common with other cells in the hippocampal formation, the angular position of MEC cell activity is controlled by the cue card. Also in common with place cells and head direction cells (theta cells and subicular cells were not tested), preliminary data suggest that MEC firing patterns persist following card removal. This finding implies that MEC cells, like the others, are not triggered in a simple sensory fashion and, taken together with the lack of strong behavioral modulation, supports the notion that MEC cells primarily signal location.

In contrast to the similar effects of card manipulations on MEC and place cells, changing the apparatus shape strongly differentiated the two cell types. In agreement with Muller and Kubie (1987), we found that the shape change caused the firing patterns of hippocampal place cells to be drastically altered in one of two ways. First, a cell with a firing field in one apparatus may be virtually silent in the other. Second, if a place cell has a field in both apparatuses, there is no relationship between the ficlds that is consistent over the population. In other words, the location of a firing field in one chamber does not predict field location, or even the existence of a field in the other. MEC cell discharge, on the other hand, is much less affected by changing the apparatus shape. In no case did an MEC cell become virtually silent after moving the rat from the cylinder to the square. Of equal importance is evidence that the positional firing patterns of many MEC cells in the cylinder and square are topologically related, such that the transformation mimics the topological relationship between the cylinder and the square. 
The topological changes in MEC cell discharge caused by changing apparatus shape suggest that a cell is triggered whenever cach of several cell-specific stimulus features falls within a certain range at the same time. In this view, the mimicry of shape change by firing pattern change is a result of the fact that many stimulus features are likely to covary with position in the same way in the cylinder and square. In contrast to the cardremoval finding, the response of MEC cells to changing the apparatus shape seems to be more bound to sensory cues than hippocampal place cells. Card removal, on the other hand, shows that MEC cell firing is not "locked" to sensory cues. Thus, MEC cells are more bound to sensory information than the cells they project to, but are not the simple sensory cells one finds in even earlier stages in sensory pathways. A serial model of information processing would predict that the firing of cells afferent to entorhinal cortex might show an even greater level of dependence on sensory cues. Further experiments are required to test this prediction.

\section{$M E C$ as an input to the hippocampus}

In the analysis of sensory or motor systems, it is often convenient to treat information flow in steps that take place between pairs of anatomically separated areas. A goal of this sort of analysis is to describe the transform that carries firing in the "source" region into firing in the "destination" region, even if it is clear that the description does not take other anatomical realities into account.

The treatment of the input from superficial MEC to the hippocampus given here is justified in the first place by the anatomical fact that the superficial layers send axons to the hippocampal formation via the perforant path (Steward and Scoville, 1976). Our focus on the projection from MEC to the hippocampal formation assumes that a partial understanding of spatial information flow in the hippocampal area is possible before the firing properties of cells in all the relevant components of the hippocampal area are known. In particular, the treatment ignores (1) the parallel projection to the hippocampal formation from lateral entorhinal cortex; (2) the fact that MEC projects monosynaptically to the dentate gyrus, $\mathrm{CA} 1$, and $\mathrm{CA} 3 / 4$; (3) the relay from dentate to $\mathrm{CA} 3$; and (4) the Schaffer collateral projection from $\mathrm{CA} 3 / 4$ to $\mathrm{CA} 1$ and any differences between $\mathrm{CA} 1$ and $C A 3 / 4$ place cells. In contrast, our data allow us to speculate on the significance of the superificial-MEC/hippocampal loop that is completed by direct and indirect projections from the hippocampus to deep layers of MEC (via subiculum, prcsubiculum, and parasubiculum) and connections from deep to superficial layers of MEC.

As noted above, we found two major differences between the positional firing of MEC and place cells. The first is the higher correlation between position and discharge rate for place cells. Given that MEC cells supply information to place cells, the crisper firing of place cells can be described as a form of signal enhancement that is performed by the network; a noisy positional signal is cleaned up. Signal enhancement could take place in many ways. For example, Berger et al. (1980) suggested that hippocampal cells serve to amplify a weak input signal during the course of classical conditioning, a description that is also reasonable in the present case. Alternatively, the improved positional signal in hippocampal cells might result from convergent input from many noisy entorhinal cells with similar firing patterns, or a process akin to lateral inhibition.

The anatomical locus of signal enhancement is uncertain.
There arc two paths from MEC to hippocampus: one to the dentate, which in turn projects to $\mathrm{CA} 3$ (with CA3 projecting to CA1), and a direct projection from MEC to CA1 and CA3. Jarrard et al. (1984) observed deficits in maze performance after bilateral entorhinal lesions, but not after bilateral dentate lesions, suggesting that fibers in the perforant path that bypass dentate to end directly in CA3 and CAI are critical. In agreement, McNaughton et al. (1989) found that dentate lesions largely spared location-specific firing of CAl place cells, although such firing was disrupted in CA3 place cells. It is obvious that a correct description of signal enhancement requires much more knowledge about details of connectivity and activity in the hippocampal arca.

A more positive conclusion is reached from a neural network simulation of how place cell firing patterns could arise given the positional information contained in MEC cells' activity. Muller et al. (1989) used the back-propagation of error method of Rumclhart et al. (1986) with a three layer network in which the input units were $40 \mathrm{MEC}$ cells, the output layer was 40 place cells, and the middle layer consisted of 40 "hidden" units. An input pattern consisted of the firing rate of each MEC cell in a given pixel, and an output pattern of the firing rate of each place cell in the same pixel. Synaptic weights between input and hidden cells and between hidden and output cells were adjusted according to the generalized delta rule, where the change in synaptic weight depends on the difference between the calculated output rate and desired output rate of each place cell in the given pixel. The adjustment of synaptic weights was then repeated for each pixcl, to complete an "epoch" (Rumelhart et al., 1986). Training was continued for 1000 epochs, after which comparisons were made between the positional patterns generated at the output layer and the original positional firing patterns of the place cells. As judged by inspection of color-coded rate maps, it was found that the network could accurately reproduce the original place cell patterns. For a fixed number of epochs, the precision of the reproduction was greater when the input MEC cells were selected for high coherence. This is a formal demonstration that MEC firing contains enough positional information to permit place cell firing. It should be stressed, however, that the demonstration in no way implies that back-propagation operates in vivo.

The second major difference between the positional firing patterns of MEC and place cells is the more profound effect that changing the apparatus shape has on place cells. This finding raises questions about the anatomical relationship entorhinal cortex has with the hippocampus as both an input and an output. MEC fibers arise from superficial layers of MEC, and the indirect hippocampal input goes to deep layers of MEC; an MEC/hippocampus loop is completed by connections from deep to superficial MEC. On anatomical grounds alone, therefore, it is possible that the location-specific firing of superficial MEC cells is derived from that of place cells instead of the more conventional view that the main information flow is from superficial MEC to hippocampus.

It is our contention that the apparatus shape experiment provides powerful evidence that MEC activity is an antecedent of place cell activity. When the rat is shifted from the cylinder to the square, MEC cells undergo topological transforms of their positional firing patterns, whereas the firing patterns of hippocampal place cells are unrelated in the two chambers. There are plausible mechanisms by which the closely related MEC cell firing patterns could be operated on to generate extremely dis- 
similar hippocampal firing patterns; one such scheme is mentioned below. On the other hand, the reverse process in which topologically related firing patterns in superficial MEC are produced by operating on unrelated patterns is much harder to imagine. We conjecture that the transformation from superficial MEC to hippocampus is irreversible; information about topological similarity is lost when two independent active subsets of place cells are used to represent the cylinder and square.

\section{Environmental representations and cell populations}

Common properties of the population representations. At the population level, MEC units share several important properties with place cells. First, both representations are stable in time. This is known from the constancy of the positional firing pattern of each cell whenever the rat returns to a familiar environment, regardless of the rat's intervening experience and regardless of any changes in positional firing that happen when the rat is in a different environment (Muller and Kubie, 1987; Bostock ct al., 1991). Because the representations are not time variant, it is possible for the activity of the populations to signal the rat's position unambiguously; each position is associated with a unique list of firing rates for all the MEC cells and separately for all the place cells.

Second, the centers of MEC cell firing patterns are distributed evenly over the surface of the apparatus, in parallel with the even distribution of field centers for place cells. In particular, there is no tendency in cither case for the regions of most rapid firing to occur near the cue card. The even density of cells that represent the apparatus surface has two implications. At the neural level, it is clear that the instantaneous firing rate averaged over all the cells in each population is ncarly independent of the rat's position; which cells discharge varies, but the total number of action potentials per unit time is constant. At a more abstract level, it is possible to argue that the absence of preferred regions implies that the representations are maplike. Alternatively, the even densities may reflect the fact that pellet retrieving gives each region equal "reward value," a hypothesis suggested by the observations of Breese et al. (1989). In our view, however, more recent work by Speakman and O'Keefe (1990) reinforces the idea that goal location has little influence on place cell firing.

A third common feature of the two populations is the apparent lack of a topographic relationship between the surface of the apparatus and the surfaces of the two cortical areas; neighborliness of environmental points is not preserved as ncighborliness of cells on the cortical surfaces. We saw no obvious tendency for the firing patterns of neighboring MEC cell pairs (simultaneously recorded from a single electrode) to be preferentially overlapping or adjacent. Muller and Kubie (1987) and Bostock et al. (1991) reported the same outcome for place cells pairs recorded from one wire. A contrasting view is presented by Eichenbaum et al. (1989), who argue for weak topography.

Differences between the $M E C$ and hippocampal representations. When considering cell discharge in a single, familiar environment, our results do not suggest a vast difference in the representations provided by MEC and the hippocampus. It is true that the location-specific firing of single MEC cells is locally noisier, but the difference is only one of degree. If MEC had

\footnotetext{
${ }^{3}$ If superficial MEC mainly serves as a way station for the highly processed sensory information that supports place cell firing, the indircct input from hippocampus to superficial MEC likcly carries less-specific information. One possibility is that the return pathway acts like an automatic gain control, so that the total drive on place cells is kept constant.
}

been investigated first, it would have been plausible to postulate it as the anatomical locus of a map of the environment.

An entirely different view emerges if recordings are made in different environments. If two environments (e.g., the cylinder and square) are sufficiently different, their representations across the place cell population scem to be independent of each other. As noted above, a cell may be silent in each environment, active in only one or in both; if it is active in both, the firing fields bear no relationship to each other that generalizes to other cells. The existence of place cells that have fields in one chamber and are silent in another naturally gives rise to the idea of a chamberspecific "active subset" of the population (Kubie and Ranck, 1984; Muller and Kubie, 1987; Bostock et al., 1991). The best estimate of about $15 \%$ for the size of the active subset is provided by the work of Thompson and Best (1989). It thus appears that the place cell population signals two important types of information that can be read by an outside observer, regardless of whether the information is available to the rat. First, the members of the active subset that are firing at any instant signal the position of the rat within the current environment. Second, the current environment can be distinguished from others if the components of the active subset are known. In contrast to place cells, we never saw a case in which an MEC ccll became silent when the rat was transferred from the cylinder to the rectangle. Thus, the firing of hippocampal cells but not MEC cells contains sufficient information to determine not only position within the environment, but the environment itself. This difference is further suggestive of MEC cells as antecedent to hippocampal cells and raises several important questions. For example, how is the environmental representation extracted, and does it require dentate and/or lateral entorhinal cortex? With respect to active subsets, how is their stability maintained and how is the correct active subset selected when the rat is familiar with many environments? One also wonders if the concept of active subset will be valuable for other portions if the cortex, or if the hippocampus, is unique.

\section{References}

Barnes CA, McNaughton BL, Mizumori SJY, Leonard BW, Lin L-H (1990) Comparison of spatial and temporal characteristics of neuronal activity in sequential stages of hippocampal processing. Prog Brain Res 83:287-300.

Berger TW, Clark GA, Thompson RF (1980) Learning dependent neuronal responses recorded from limbic system brain structures during classical conditioning. Physiol Psychol 8:155-167.

Best PJ, Ranck JB Jr (1982) The reliability of the relationship between hippocampal unit activity and sensory-behavioral events in the rat. Exp Neurol 75:652-664.

Bostock FM, Muller RU, Kubie JL (1991) Experience-dependent modifications of hippocampal place cell firing. Hippocampus 1:193206.

Breese CR, Hampson RE, Deadwyler SA (1989) Hippocampal place cells: stereotypy and plasticity. J Neurosci 9:1097-1111.

Deacon TW, Eichenbaum H, Rosenberg P, Eckmann KW (1983) Afferent connections of the perirhinal cortex in the rat. J Comp Neurol 220:168-190.

Eichenbaum H, Cohen NJ (1988) Representation in the hippocampus: what do hippocampal neurons code? Trends Neurosci 11:244-248.

Eichenbaum H, Wiener SI, Shapiro ML, Cohen NJ (1989) Functional correlates of hippocampal neurons. III. The organization of spatial coding in neural cnscmbles. J Ncurosci 9:2764-2775.

Fox SE, Ranck JB Jr (1975) Localization and anatomical identification of theta and complex spike cells in the dorsal hippocampal formation of rats. Exp Neurol 49:299-313.

Fuller JH, Schlag JD (1976) Determination of antidromic excitation by the collision test: problems of interpretation. Brain Res 112:283298. 
Goodlett CR, Nichols JM, Halloran RW, West JR (1989) Long-term deficits in water maze spatial conditional alternation performance following retrohippocampal lesions in rats. Behav Brain Res 32:6367.

Haug F-MS (1976) Sulphide silver pattern and cytoarchitectonics of parahippocampal areas in the rat. Adv Anat Embryol Biol 52:7-73.

Jarrard LE (1983) Selective hippocampal lesions and behavior; effects of kainic acid lesions on performance of place and cue tasks. Behav Neurosci 97:873-889.

Jarrard LE, Okaichi H, Steward O, Goldschmidt RB (1984) On the role of hippocampal connections in the performance of place and cue tasks: comparisons with damage to hippocampus. Behav Neurosci 98:946-954.

Johnson CT, Olton DS, Gage FH III, Jenko PG (1977) Damage to hippocampus and hippocampal connections: effects on DRL and spontaneous alternation. J Comp Physiol Psychol 3:508-522.

Jones EG, Powell TPS (1970) An anatomical study of converging sensory pathways within the cerebral cortex of the monkey. Brain 93: 793-820.

Kohler C (1986) Intrinsic connections of the retrohippocampal region in the rat brain. II. The medial entorhinal area. J Comp Ncurol 246: 146-149.

Kubie JL (1984) A drivable bundle of microwires for collecting single unit data from freely moving rats. Physiol Behav 32:115-118.

Kubie JL, Ranck JB Jr (1984) Hippocampal neuronal firing, context, and learning. In: Neuropsychology of memory (Squire LR, Butters N, eds), pp 417-423. New York: Guilford.

Kubie JL, Dayyani S, Sutherland RJ, Muller RU (1989) Hippocampal lesions disrupt acquisition but not retention of navigational behavior in a highly familiar environment. Soc Neurosci Abstr 15:609.

Kubie JL, Muller RU, Bostock EM (1990) Spatial firing properties of hippocampal theta cells. J Neurosci 10:1110-1123.

McNaughton BL, Barnes CA, O'Keefe JO (1983) The contribution of position, direction, and velocity to single unit activity in the hippocampus of freely moving rats. Exp Brain Res 52:41-49.

McNaughton BL, Barnes CA, Meltzer J, Sutherland RJ (1989) Hippocampal granule cells are necessary for spatial learning but not spatially-sclective pyramidal cell discharge. Exp Brain Res 52:41-49.

Miller VM, Best PJ (1980) Spatial correlates of hippocampal unit activity are altered by lesions of the fomix and entorhinal cortex. Brain Res 194:311-323.

Morris RGM, Garrud P, Rawlins JNP, O'Keefe J (1982) Place navigation impaired in rats with hippocampal lesions. Nature 297:681683.

Muller RU, Kubie JL (1987) The effects of changes in the environment on the spatial firing of hippocampal complex-spike cells. J Neurosci 7:1951-1968.

Muller RU, Kubie JL (1989) The firing of hippocampal place cells predicts the future position of freely moving rats. J Neurosci 9:41014110.

Muller RU, Kubie JL, Ranck JB Jr (1987) Spatial firing patterns of hippocampal complex-spike cells in a fixed environment. J Neurosci 7:1935-1950.

Muller RU, Quirk GJ, Kubie JL (1989) Back-propagation calculations of hippocampal place cell firing fields. Soc Neurosci Abstr 15:403.

O'Keefe J (1976) Place units in the hippocampus of the freely moving rat. Exp Neurol 51:78-109.

O'Keefe J, Conway DH (1978) Hippocampal place cells in the freely moving rat: why they fire where they fire. Exp Brain Res 31:573-590.

O'Keefe J, Dostrovsky J (1971) The hippocampus as spatial map. Preliminary evidence from unit activity in the freely moving rat. Brain Res 34:171-175.

O'Keefe J, Nadel L (1978) The hippocampus as a cognitive map. London: Clarendon.
O'Keefe J, Speakman A (1987) Single unit activity in the rat hippocampus during a spatial memory task. Exp Brain Res 68:1-27.

Olton DS, Walker JW, Gage FH (1978a) Hippocampal connections and spatial discrimination. Brain Res 139:295-308.

Olton DS, Branch M, Best P (1978b) Spatial correlates of hippocampal unit activity. Exp Neurol 58:387-409.

Olton DS, Walker JA, Wolf WA (1982) A disconnection analysis of hippocampal function. Brain Res 233:241-253.

Quirk GJ, Muller RU (1989) The firing of entorhinal place cells is more sensory-bound than that of hippocampal place cells. Soc Neurosci Abstr 15:404.

Quirk GJ, Ranck JB Jr (1986) Firing of single cells in entorhinal cortex is location-specific and phase locked to hippocampal theta rhythm. Soc Neurosci Abstr 12:1524.

Quirk GJ, Muller RU, Kubic JL (1990) The firing of hippocampal place cells in the dark reflects the rat's recent experience. J Neurosci 10:2008-2017.

Ranck JB Jr (1973) Studies on single neurons in dorsal hippocampal formation and septum in unrestrained rats. Exp Neurol 41:461-555.

Rumelhart DE, Hinton GE, Williams RJ (1986) Learning internal representations by error propagation. In: Parallel distributed processing: explorations in the microstructures of cognition. Vol I (Rumelhart DE, McClelland JL, eds), pp 318-362. Cambridge, MA: MIT Press.

Ruth RE, Collier TJ, Routtenberg A (1982) Topography between the entorhinal cortex and the dentate septotemporal axis in rats. I. Medial and intermediate entorhinal projecting cells. J Comp Neurol 209:6978.

Schenk F, Morris RGM (1985) Dissociation between components of spatial memory in rats after recovery from the effects of retrohippocampal lesions. Exp Brain Res 58:1 1-28.

Sharp PE, Kubie JL, Muller RU (1990a) Firing properties of hippocampal neurons in a visually-symmetrical stimulus environment: contributions of multiple sensory cues and mnemonic processes. $J$ Neurosci 10:3093-3105.

Sharp PE, Ranck JB, Muller RU (1990b) Direction and location correlates of cell firing in the rat subiculum. Soc Neurosci Abstr 16:737.

Speakman A, O'Keefe J (1990) Hippocampal complex spike cells do not change their place fields if the goal is moved within a cue controlled environment. Eur J Neurosci 2:544-555.

Steward O, Scoville S (1976) Cells of origin of entorhinal cortical afferents to the hippocampus and fascia dentata of the rat. J Comp Neurol 169:347-370.

Sutherland RJ, Wishaw IQ, Kolb B (1983) A behavioral analysis of spatial localization following electrolytic, kainate- or colchicine-induced damage. Behav Brain Res 7:133-153.

Taube JS, Muller RU, Ranck JB Jr (1990a) Head direction cells recorded from the postsubiculum in freely moving rats. I. Description and quantitative analysis. J Neurosci 10:420-435.

Taube JS, Muller RU, Ranck JB Jr (1990b) Head direction cells recorded from the postsubiculum in freely moving rats. II. The effects of environmental manipulations. J Neurosci 10:436-447.

Thompson LT, Best PJ (1989) Place cells and silent cells in the hippocampus of freely-behaving rats. J Ncurosci 9:2382-2390.

Wiener SI, Paul CA, Eichenbaum H (1989) Spatial and behavioral corrclates of hippocampal neuronal activity. J Neurosci 9:2737-2763.

Witter MP, Groenewegen HJ, Lopes da Silva FH, Lohman AH (1989) Functional organization of the extrinsic and intrinsic circuitry of the parahippocampal region. Prog Neurobiol 33:161-253.

Yeckel MF, Berger TW (1990) Feedforward excitation of the hippocampus by afferents from the entorhinal cortex: redefinition of the role of the trisynaptic pathway. Proc Natl Acad Sci USA 87:58325836. 